\title{
Characterization of nanomedicines: a reflection on a field under construction needed for clinical translation success
}

\author{
Jean-Baptiste Coty, Christine Vauthier*
}

Institut Galien Paris-Sud, CNRS, Univ. Paris-Sud, Université Paris-Saclay, 5 rue Jean-Baptiste Clément, 92290 Châtenay-Malabry, France

Published in: J Control Release. 2018;275:254-268. doi: 10.1016/j.jconrel.2018.02.013.

*Corresponding author: Dr. Christine Vauthier, CNRS UMR 8612, Institut Galien Paris Sud, Univ. Paris-Sud, Université Paris-Saclay, 5, rue Jean-Baptiste Clément, 92296 ChâtenayMalabry, France. Fax: +33 146835946. E-mail: christine.vauthier@u-psud.fr

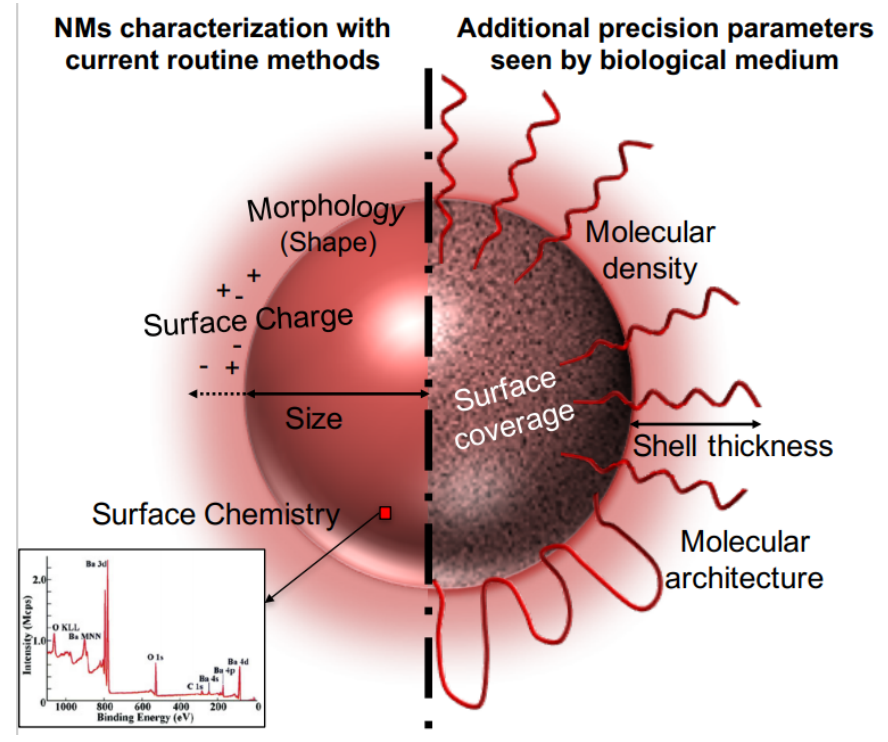

Abstract. The nanotechnology revolution offers many expectations for the improvement of medicine treatments. At present, nanomedicine (NM) development is hampered by methodological barriers for a better characterization and a wider understanding of their in vivo behavior. While regulatory agencies setup guidelines to support NM translation from bench to bedside, the gap is still hardly overcome by main nanomedicines. One lever for filling this gap is a better characterization, thus increasing the global knowledge about the NM itself but also validate the confidence in terms of batch-to-batch reproducibility of such complex nano-objects. Here, we review the current methodologies routinely used for clinical release of nanomedicine batches in compliance with official guidelines. We confront them to the extreme sharpness of biological systems and finally discuss future possible orientations for a better characterization of NMs, needed to bridge the gap between physicochemical properties and biological fate.

Keywords: Characterization, nanomedicine, regulatory, biological systems, quality control 


\section{Introduction}

Since the early age of nanotechnologies, nanomedicines (NMs) are considered as a revolutionary way to design medicines bringing high potential for the development of treatments for non-curable diseases and for diseases of severe prognostic (e.g. cancer, infections, cardiovascular diseases, neurodegenerative deseases). While mainly conceived as drug delivery carriers for targeting purposes since their early ages, some nanomaterials are now also developped as therapeutic agents on their own. Among them, reactive oxygen species promoters [1], Xray enhancers [2] or hyperthermia agents [3] are being developed. As a consequence, an increasing number of emerging small companies as well as big pharmas are exploring the Nanomedicine's field for its promises [4-6]. However, the number of 50 marketed NMs (among which the most known AmBisome ${ }^{\circledR}$ (1990), Doxil ${ }^{\circledR}$ (1995), Abraxane ${ }^{\circledR}$ (2005), Onivyde ${ }^{\circledR}$ (2015)) appears inconsistently low compared with the tremendous research activities in academics and clinics [7-10]. The gap for the translation of advances made in research laboratories to the patient is so huge that it earned the title of "Death Valley" [11]. Many challenges have been identified as bottlenecks for the clinical translation of NMs. Designing efficient nanomedicines requires a better understanding of their mechanisms of action including the interactions occurring between NMs and biological systems. In turn, a better knowledge of NMs' characteristics is needed to complete this understanding. Another part concerns the production of nanomedicines including the scale-up of preparation methods and quality controls that are needed to achieve batch to batch consistency $[11,12]$. In both cases, the achievement of a relevant characterization of NMs is needed. At present, it is still a difficult task to fix. One reason is the need to further understand which parameters are governing their in vivo fate and activity. A second reason is found in the few number of methods that are operational to achieve a precise and relevant characterization of nanomedicines on a daily basis.

The purpose of the present review paper was to discuss the physicochemical characterization of NMs considering differences in characteristics that can be detected by biological systems with potential influence on their in vivo fate, hence interfering with their activity and safety. As the world of Nanomedicine includes several types of nanotechnologies, this analysis considered nanoparticles (NPs) with a size significantly larger than that of blood proteins, which vary from few to $15 \mathrm{~nm}$. The analysis also focused on NMs intended to be administered by the intravenous route, as they represent most of the systems considered in development of treatments for cancer, severe infections and neurodegenerative diseases among all nanotechnologies developed as nanomedicines $[13,14]$. The first part of the paper analyses the physicochemical parameters that are relevant from biological systems' side to discriminate NMs (part I). Then, a review of the present recommended strategies for NMs characterization in the light of guidelines provided by health agencies was made in part II. The two next parts discuss properties and methods regarding NMs characterization. Those that are readily 
applicable for quality control analyses were presented in part III. Then, characteristics that may be interesting to evaluate due to their relevance regarding their influence on biological system responses were discussed (part IV). Other potentially interesting methods currently in development were also presented in this part.

\section{Relevant physicochemical characteristics of nanomedicines detected by biological systems with implication on their in vivo fate}

\section{I.1. The mystery of NMs in vivo fate is driven by their pristine properties}

One concern in clinical development of nanomedicines is to be able to warrant their safety and the reproducibility of their activity from batch to batch. The same consideration applies in the development of generic nanomaterials (nanosimilars). Here, it is proposed to examine differences in physicochemical characteristics that biological systems can detect with implication on the in vivo fate of nanomedicines and potential impacts on their activity and safety.

Obviously, the in vivo fate of NMs introduced in the bloodstream is governed by interactions with components of the different biological environments and barriers found on their way to the site of action. Understanding these interactions and controlling NMs' characteristics that are influencing them are challenges for the development of safe and efficient NMs $[15,16]$. So far, most works focused on the understanding of interactions occurring directly after NMs introduction in the bloodstream. This is consistent with the fact that events happening at this stage have a tremendous implication on NMs' biodistribution $[17,18]$. This has been understood in the early development of NMs and led to the definition of two types of NMs with distinct pharmacokinetics (PK). NMs showing a long half-life (hours) in the bloodstream were classified as "stealth" while "non-stealth" NMs are rapidly cleared from the bloodstream (within minutes) and accumulate in organs rich in macrophages (liver, spleen) [19-23]. Recently, efforts were intensified to identify more precisely NMs' characteristics controlling these interactions [24-27]. Understanding the linkage between the pristine synthetic properties of the NMs and their in vivo fate requires a lot of data gathering the behavior of series of NMs with perfectly known synthetic identity. Such studies have been the subject of only a limited number of works in the literature. Some of them were mentioned below regarding interactions of NMs with blood proteins and cells. At the end of this part, two additional examples illustrating the high sensitivity of biological systems, able to detect subtle changes in structural characteristics of entities they are confronted with are presented. These examples were taken from Mother Nature as it was not done before in studies involving NMs. 


\section{I.2. NMs characteristics controlling their interactions with blood proteins}

It is now well established that interactions between nanomedicines and blood proteins are particularly decisive regarding the behavior of the NM in the body. The in vivo fate as well as the efficacy and safety of the administered NMs are greatly influenced by their interaction with proteins of surrounding media $[17,18]$. The adsorption phenomenon of proteins on NMs forming the so called "protein corona" has not been cleared up regarding the properties of the NMs. However, it has been shown that the adsorption of specific proteins could greatly influence the biodistribution of the NM [28-30] or activate their recognition by innate immunity. Interactions with proteins greatly depends on the NM characteristics. As it will appear bellow, several measurable characteristics are influencing the way proteins interact with NM. Yet, recent data suggests that knowing only these characteristics is insufficient to fully understand how proteins interact with the NM and how nanoparticles are controlling the selectivity of the interaction or the initiation of biochemical cascades. Today, two distinct ways have been proposed to improve our general understanding on characteristics of NM that influence their interaction with proteins.

(i) The identification of the "adsorbome" of proteins forming the protein corona around the NM, providing a new biological identity supplanting the initial synthetic identity of the nanomaterial [31]. It consists in the identification of the proteins adsorbed onto the NM after contact with plasma. The throughput and accuracy of such a study has been greatly improved by the development of dedicated systems of liquid chromatography coupled to mass spectrometry (LC-MS). Among these studies, several parameters of NMs have been pointed out for their influence on this adsorbome [32-34]. More precisely, the size [35-39], the shape [40], but even more the surface chemistry and the charge of NMs influencing the hydrophilicity/hydrophobicity of the nanoparticle surface were found to strongly impact the protein corona composition [36,38,41-45]. While polyethylene glycol (PEG) chain grafted on NMs' surfaces have been widely studied since the middle of the 1990's [23,46-48], other surface chemistries are being explored for their stealth properties too (polysaccharides, synthetic surfactants) [49-51]. Besides, these studies showed that for a given chemical nature, the length, the density as well as the conformation of macromolecules grafted on the surface were determinant regarding interactions with proteins [47,52-54], emphasizing the need for a precise characterization of NMs' surface properties and control of the surface architecture too. It is worth noting that the homogeneity of such a grafted layer at the surface of the NM might be a paramount criterion regarding the adsorbome profile.

(ii) The assessment of interactions with proteins of biochemical cascades is another way to study interactions of NMs with blood proteins more directed towards safety $[55,56]$. Coagulation and 
complement systems are composed of groups of proteins that regulate body's homeostasis towards foreign agents. So far, most studies have focused on the interactions between NMs and the complement cascade, which is directly linked to the immunocompatibility of the considered nanomaterial. Complement proteins are part of the first barrier of innate immunity encountered by the nanomaterial in the blood. A premature detection of NMs by this system leads to their opsonization and capture by macrophages. NMs are then mainly retained in the liver hence biasing all their biodistribution. It was even recently reported that the protein corona could prevent from macrophage uptake [57]. Several studies showed that above cited NMs properties influenced the triggering of this cascade [58-60]. Once again, the surface architecture has been proved to be very important concerning complement activation with different type of macromolecules composing the NP shell (PEG [61-65], polysaccharides [66-70]). On the other hand, interactions of NMs with proteins and cells of the coagulation system are important because they can lead to reactions such as hemorrhage, or conversely, thrombosis [71]. A review by llinskaia et Dobrovolskaia described some known interactions between different kind of nanomaterials and the coagulation system [72]. It emphasized that NMs' size, charge and surface composition were also involved in interactions with the coagulation system. Presently, due to the lack of knowledge about the surface molecular architecture of NMs, we have no idea of the influence of this parameter on the interactions with the coagulation system, while it appears as clearly impacting complement activation and protein adsorption pattern of NMs.

\section{I.3. NMs characteristics controlling their interactions with cells}

To promote interactions with target cells, ligands can be attached on the nanoparticle surface. In general, NPs bearing such ligands are more likely to be taken up by cells exhibiting the corresponding receptors [73-76]. Little is known about the number of requested ligands per nanoparticle to improve its internalization by the target cells. It is also not clear whether the distribution of ligands and coating materials influences interactions with cells. It can be reasonably assumed that the internalization pathway is defined by the type of targeted receptor in this case. Besides, nanoparticles can be internalized by cells even in the absence of targeting moiety by several mechanisms (e.g. phagocytosis, clathrin mediated endocytosis, caveolae dependent endocytosis, macropinocytosis) [77-80]. Some studies showed the importance of surface charge, geometry and even architecture on cellular uptake of NMs $[78,79,81-84]$. However, very little is known about how nanoparticle characteristics control cell internalization phenomenon, which is also directly linked to the type of cell considered. The situation is even more complex since the above-mentioned protein corona has been identified to also influence the cellular uptake $[52,81,82,85-88]$. Today, only punctual observations are available without enough comparative studies allowing a better understanding of critical parameters driving interactions 
between cells and NMs. The correlation between synthetic parameters of the NM, biological acquired identity and cellular uptake is not understood although computational models are being established to connect them $[36,89,90]$. Once in the cell, the intracellular trafficking defines the fate of NMs and thus their therapeutic efficacy. This part greatly depends on the uptake mechanism as well as NMs properties and is still not totally understood neither. Besides, the targeting of NMs to a specific organelle is not an easy task. It is expected that a design of NMs properties make them able to at least escape the endosome in order to produce the expected activity $[77,78,80]$. The way towards this control is still not cleared today. A last interrogation on current studies about NM-cells interactions was raised the influence of the dye incorporated in NMs in order to trace them. It was shown that the nature of the dye itself could impact on cell uptake and that observed results can be due to dye leakage from the NM [91].

\section{I.4. Concluding remarks in the light of examples taken in biological systems found in Mother nature}

As pointed out above, modifications in the surface architecture of nanoparticles can dramatically affect the way these nano-objects developed as nanomedicines are seen by the organism after intravenous injection, with possible influence on their in vivo fate. This is due to the high sensitivity of biological systems that are capable to distinguish very small structural differences that may occur at a molecular level. Unfortunately, this degree of precision is not fully considered in NMs' design today. The extremely high degree of precision shown by biological systems is further illustrated below through two examples taken from Mother Nature.

At first, the bacterial capsules of Neisseria meningitidis ( $N$. meningitidis) embody the sensitivity of biological systems. Among them, the sialic acid capsular polysaccharides expressed by N. meningitidis serogroups $B$ and $C$ are very similar $[92,93]$. The complexity of the finding of an efficient vaccine against $N$. meningitidis serogroup B comparatively to the serogroup C was explained by the nonimmunogenicity of the B serogroup and its ability to escape the immune system [94]. This form, not detected by the immune system, is responsible for severe infections while serogroups $A$ and $C$ types are more easily cleared. This is due to the capsule conformation which has a very strong impact on the becoming of the bacteria in the host body. The difference lies in the substitution differing from one carbon on the polysaccharide capsule: while $N$. meningitidis serogroup $C$ has a poly(alpha 2-9 acid acetyl neuraminic) capsule composition, the B type capsule is made of poly(alpha 2-8 acid N-acetyl neuraminic) $[93,95]$ (see Fig. $1 \mathrm{~A}$ ). This small chemical change implies a conformation modification of the final sialic acid, which modifies negative charges exposure and steric hindrance effects $[96,97]$. It has also been proofed that $N$. meningitidis serogroup B capsule composition was similar to those found 
in an endogen neuronal protein, playing a great role in its non-immunogenicity [98]. This is an example showing the extreme sensitivity of biological systems, that can be recognized or not depending on the displacement of substitution of one carbon in the chain, inducing conformational changes in the final structure. This example easily translates to the NMs field with the importance of the surface architecture on their in vivo fate, hence the degree of precision required for NMs synthesis and characterization.

Then, the antigen-antibody interaction is another proof of the sensitivity of biological systems. Modification of few amino acids in a chain of more than 1300 amino acids allows a dramatic change in antigen-antibody interaction. Indeed, a sequence of five amino acids is responsible for the specific interaction between an antigen and an antibody that form an antigen-antibody complex with an extremely high specificity. Modification of one or several amino acids on the paratope and/or epitope can reduce the strength of the interaction by three orders of magnitude, thus hampering the formation of the complex [99]. These interactions are a combination of electrostatic interactions added to a favorable conformation of the epitope's chain [100]. While Immunoglobulins $\mathrm{G}$ are proteins around 10 $\mathrm{nm}$ in size, their action is driven by a couple of amino acids. A study was performed to identify key residues involved in interactions between platelet receptor glycoprotein Iba (GPIba) and a monoclonal antibody 6B4, that could be used as an inhibitor of overexpressed interaction of GPIba with Von Willebrand Factor that can lead to thrombosis [99]. It was shown in the paratope-epitope simulation of $\mathrm{H}$-bond interaction mapping for protein and monoclonal antibody $6 \mathrm{~B} 4$ that four amino acids from the antibody paratope and 2 amino acids from the protein epitope are strongly involved in the affinity between the two entities (red colors in Fig. 1B). Translating this example to the NM field, this is typically the complex issue observed in the grafting of targeting moieties on NMs. Most of these moieties are antibodies, RNA, aptamers or even proteins, grafted in a targeting purpose to be recognized by receptors on specific cells. However, current coupling methods used with these complex molecules are not precise enough to choose the exact location of grafting. Moreover, characterization methods are not sensitive enough to determine in which conformation the grafted moiety stands on the nanoparticle surface. This is a huge issue encountered today in NMs design and characterization $[24,27]$. Thus, it is difficult to assess the efficacy of such targeting strategy and the way to improve it since it is not possible to achieve a precise characterization yet.

These examples, combined to all the data gathered on the influence of NMs characteristics on their interactions in vivo after an intravenous administration, highlight the great importance of the required keenness for NMs characterization. As seen, a modification of NM surface architecture can be at the root of major changes in terms of biodistribution. Hence, the NM design is a very subtle process which impacts the becoming of the NM from its entry into the bloodstream to its fate inside cells. The 
sharpness of the elements and processes encountered in vivo requires a very fine control, characterization and understanding of these initial parameters.

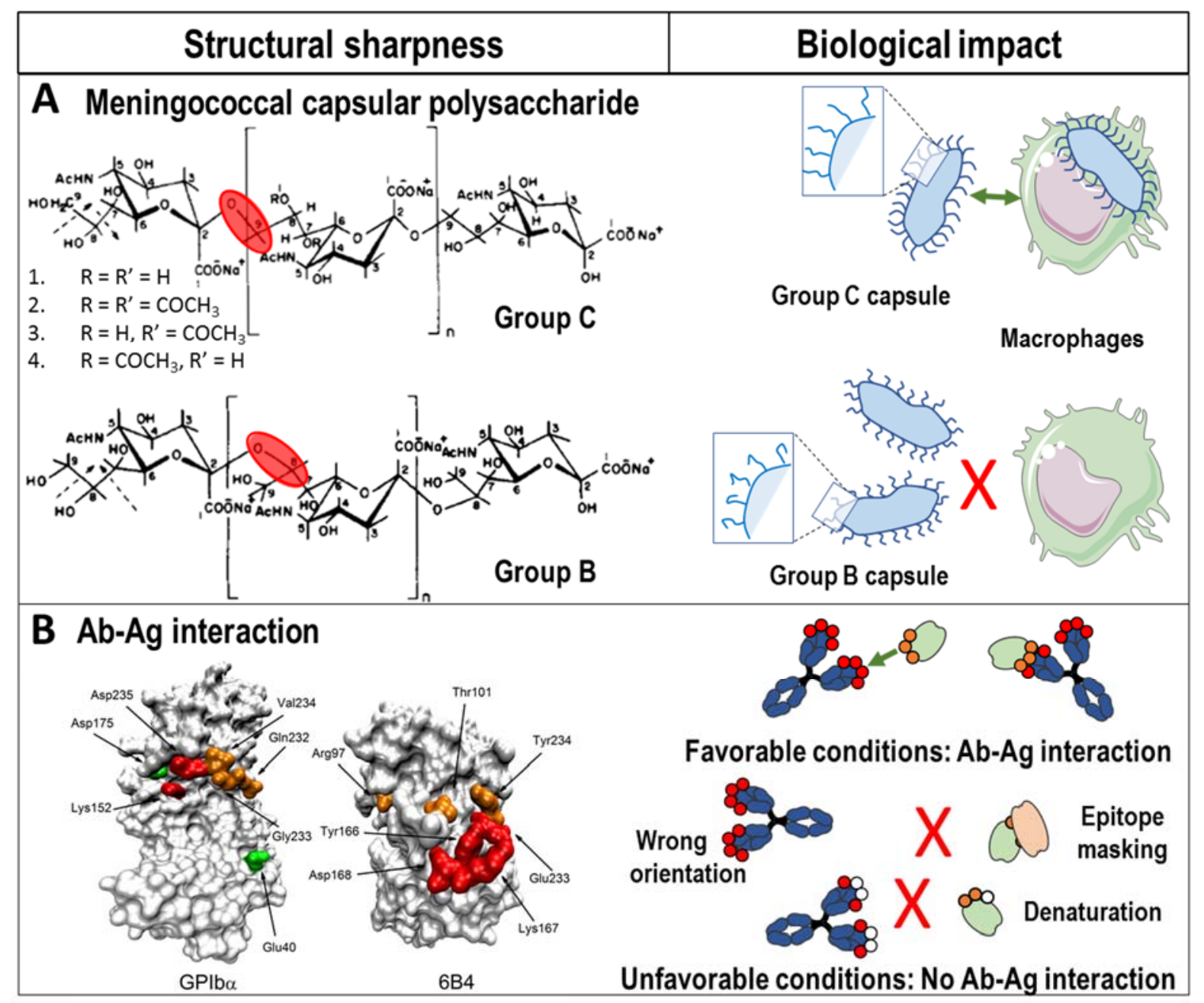

Figure 1: Examples of structural sharpness found in Mother Nature and their biological impact. A: polysaccharide structure of $N$. Meningitidis capsules of $B$ and $C$ serogroups. The red circle indicates the difference in the chemical structure between the two polysaccharides. Left part reproduced from [95] with permission from The American Association of Immunologists, Inc. Copyright 1981.

B: Identification of amino acids involved in antibody-antigen recognition. When amino-acids included in the epitopes are masked, denatured or mis-oriented, interactions between antibody (Ab) and antigen ( $\mathrm{Ag}$ ) are compromised. Left part reproduced from [99] with permission. Red amino acids represent the key amino acids in the interaction between the GPIba protein and 6B4 antibody. 


\section{General strategies for nanomedicine characterization and today's recommendations of health authorities}

\section{II.1. The characterization revolution brought by "nano"-medicines}

It is now well established that a lack of proper and rational characterization is one of the main blocking steps of NMs translation from bench to bedside [26,101,102]. Firstly, the lack of established characterization at a preclinical stage is one of the bottlenecks for nanomaterials access to the market [103]. Then, an incomplete characterization of batches during clinical testing reduces the strength of NMs assessment in clinics. This is acknowledged by the fact that developments of many formulations are being stopped while it is believed that several of the encountered problems could have been probably better anticipated with a proper characterization of the NM.

Due to the disrupting complexity of nano formulations, traditional approaches for medicine regulation cannot be applied without a significant adaptation to the nature of the pharmaceutical object $[104,105]$. The emergence of the field of Nanomedicine brings a huge deal for a renewed regulatory process. Indeed, added to the nano scale, the overexpressed surface area and the multi-component composition of such technologies makes even more difficult their characterization and the understanding of their in vivo behavior. To illustrate this difficulty, Table 1 gives a brief comparison of the major differences between conventional medicines and nanomedicines including implications on their respective characterization.

\begin{tabular}{|c|c|c|}
\hline Composition & Conventional medicine & Nanomedicine \\
\hline ingredient (API) + excipients & $\begin{array}{c}\text { Complex assembly: Self-active NM } \\
\text { or API within the nanocarrier (NC) }\end{array}$ \\
\hline Transport of the API & Single molecule solubilized & $\begin{array}{c}\text { Within the NC (biodistribution and } \\
\text { release profile modified) }\end{array}$ \\
\hline Biological activity & API dependent & $\begin{array}{c}\text { NM dependent or } \\
\text { Nanocarrier + API dependent }\end{array}$ \\
\hline Characterization & $\begin{array}{c}\text { API ignature by NMR, UV, IR) } \\
\text { Solubility - Dissolution rate } \\
\text { Purity, contaminants free }\end{array}$ & $\begin{array}{c}\text { NM properties: Size, charge, } \\
\text { morphology, drug loading and } \\
\text { release }\end{array}$ \\
\hline & $\begin{array}{c}\text { Biological activity and safety } \\
\text { warranted }\end{array}$ & $\begin{array}{c}\text { Not enough to ensure full } \\
\text { biological activity and safety }\end{array}$ \\
\hline
\end{tabular}

Table 1: Major differences encountered between conventional drug medicines and nanomedicines when bridging the translation gap. 


\section{II.2. Towards new guidelines adapted to nanomedicines}

A panel of parameters to be assessed and methods have been implemented by the National Institute of Health - Nanotechnology Characterization Laboratory (NIH-NCL), created in 2004 to reach these issues related to NM clinical translation. Assay cascades for assessing physicochemical properties as well as in vitro and in vivo testing procedures were setup to guide companies developing such entities [105]. Two main categories can be distinguished, namely the non-biological and biological assays:

- The first category of methods aims to characterize intrinsic properties of the nanomedicine through its physicochemical characteristics (size, charge, composition, morphology, concentration, API loading, free of contaminants).

- The second category includes techniques investigating interactions of the nanomedicine with biological entities encountered in vivo. This involves hematocompatibility tests (hemolysis, cytokine proliferation), investigation of interferences with biochemical cascades (complement, coagulation), in vitro cellular or tissue assays and in vivo studies [106]. This part is notably pointed out in the development of nanosimilars that can have different interactions with blood components [8,107-109].

NCL has now extended to Europe since 2015 with the creation of EU-NCL (European Nanomedicine Characterization Laboratory) [110]. They give an encouraging way to fix guidelines and unavoidable parameters to be assessed for every NM before being sent to clinical studies. This process led to the assessment of new properties related to the nano- character of the new drug. Some recent reviews discussed about these evolving aspects of NMs regulation and approvals [7,10,106,111,112]. Numerous research projects have also worked on the issues planted by nanomaterial characterization with considerations on the safety and risk assessment (e.g Prosafe, NanoREG, NanoValid) [113]. They recently pointed out a need for standardization of methods to assess properties and risks associated to nanomaterials [114].

A key point that seems to be less advanced is the characterization required for the release of a NM batch prior to clinical use. Indeed, added to conventional tests for batch release of medicines, additional tests must be performed over the entire final nano-object. The complexity is greatly augmented in these systems and batch release cannot be treated the same as for "simple" drugs. As the research and potentiality offered by these new forms of medicines brings a lot of researchers and companies working on it, a strong effort of regulatory aspect has to follow this wave for a faster and safer translation to the clinics. The NCL assay cascade is valuable in a context of evaluation of the nanomedicine before its launching in clinical trials. However, once the study launched or when the product is on the market, every single batch cannot be screened for conformity taking into account all 
the considered parameters, due to the extreme tediousness of the task, associated to a considerable cost. Some critical parameters are chosen as markers ensuring the reproducibility of the NM effect once administered. Methods on this purpose may naturally be picked from the previously mentioned assay cascades. The most important is to identify a set of key parameters that will be relevant to detect a possible modification in NM characteristic influencing the in vivo behavior [115-117]. So far, it is assumed that a case-by-case selection of this set of parameters has to be made due to the huge diversity of systems encountered in the world of nanomedicines (polymer based, inorganic, lipid, nanocrystal) $[103,118]$.

\section{II.3. Health agencies positions}

Aware of the current characterization limitations, European and American regulatory agencies (European Medicine agency (EMA) and Food and Drug Administration (FDA) respectively) opened reflections about future development needed.

EMA points out the matter of batch-to-batch consistency in its reflection papers about different kinds of nanomaterials. Notably, reflection papers related to block copolymer medicinal products [119], liposomes for intravenous delivery [120] and iron based nanocolloids [121] recommended to identify critical quality attributes that will have an impact on the behavior of the NM in vivo (PK, PD, safety, efficacy). Most of the parameters cited there are not directly focused on the "nano" character of the NM. Namely, control of the raw material (lipids, copolymers, carbohydrates) for purity, composition, stability before their use in a complex system, manufacturing process (reconstitution procedure, sterility), stability over time, or again parameters related to the mode of administration (eg. osmolality, degradation rate and location, drug release rate and location) are mentioned to be controlled. Considering the characterization of the full nanomaterial by itself, quality parameters proposed are all linked to its physicochemical properties. These parameters are typically size, size distribution, surface charge, morphology, drug loading and release profile, and in vitro stability. EMA warn about the necessity to develop methods that guarantee a better reproducibility for batch release. In a communication about quality in 2014, EMA still stressed the need for more specific guidance on the quality of nanomedicines, the identification of critical parameters and the implementation of new characterization methods [122].

On the FDA side, the nanotechnology task force published in 2007 raised a scientific issue about the understanding of nanomedicine interactions with biological systems $[118,123]$. It has also been claimed that a need for new methods is urgent. Common parameters for quality were cited as size (surface area and size distribution), chemical composition (such as purity and crystallinity), surface properties (surface reactivity, surface groups, inorganic/organic coatings), solubility, shape and 
aggregation state. It was also mentioned that the NCL would be a major actor of the development of screening tools for nanomedicine characterization. Since 2007, a final guidance was published by FDA, mainly concerning nanotechnologies in food and cosmetics [124]. To our knowledge, no major update has been released directly concerning nanomedicines.

International Standard Organization (ISO) and Organization for Economic Co-operation and Development (OECD) have planted the properties of interest for nanotoxicology. These properties are similar to those mentioned by medicine agencies, i.e. particle size and size distribution, aggregation/agglomeration, shape, surface area/porosity, composition, surface chemistry, surface charge, solubility [125-127]. Meanwhile, Contract Research Organizations (CROs) in charge of quality control of NMs are focused on physicochemical properties as well, in compliance with current guidelines. Nevertheless, some biological tests are proposed as optional for NMs bearing targeting moieties [128].

To sum up, in practice, properties checked for a batch release are fixed by the company developing the NM in accordance with regulatory experts. A consensus is taken on a case-by-case basis in regard with current feasibility of such controls in routine. Apart from contaminants (impurities dosage, API degradation, residual solvents, metal traces) and basic parameters linked to the route of administration ( $\mathrm{pH}$, osmolality, pyrogen-free, endotoxin free, sterility)), only few parameters specific to the nanomaterial are requested. They are linked to the drug loading/release properties and to the characterization of several physicochemical properties of the NM consistently with available methods allowing their determination. For example, some mentioned parameters (e.g. surface properties in FDA task force [118]) cannot be properly characterized with today's accessible methods. It is noteworthy that the efficiency of current criteria used to ensure quality and reproducibility of NMs' in vivo fate are under debate $[24,129]$. It appears clear for actors in the field of pharmaceutical development that biological studies are not applicable on a routine basis in quality control purpose [112]. For instance, in vivo animal studies are generally considered unethical to be used in systematic controls above the fact that they are time consuming, requires specific facilities, highly trained labworkers and expensive. Tests performed in cell cultures can be envisaged although they are generally complex and demanding. In the following parts of this review paper, the determination of physicochemical parameters characterizing NMs was examined in terms of methodologies and discussed regarding the degree of precision of biological systems as highlighted earlier. Physicochemical parameters presently recommended for quality control evaluation of NM were considered first. The final part discusses other parameters that may be of interest to characterize pointing out the methodological outcomes. 


\section{Recommended physicochemical parameters for NMs characterization}

The list of physicochemical characteristics and recommended for testing the conformity of a NM includes size, size distribution, morphology, surface charge, surface chemistry, drug loading and releasing profile, concentration, stability. The concentration and stability are related to the population of nanomaterials included in the nanomedicine. The stability includes two aspects in the case of NMs. As for all medicines, they need to show chemical stability over time, but also the stability against aggregation or agglomeration because NMs act as a population of individual nano-objects. This is generally done evaluating the size, the size distribution, the morphology, and the surface charge to verify that these characteristics are preserved over time. Parameters included in the above-mentioned list define what is called the "synthetic identity" of the nanomaterial and are expected to influence its in vivo fate $[31,130]$.

For a clinical use, all batches of produced NMs must be submitted to a characterization cascade that aims to prove batch to batch consistency of their synthetic identity, hence warranting biological activity and safety. Methods used to achieve these characterizations must be robust, straightforward, easy to carry out on a systematic basis, affordable and, if possible, automatable. Recently, an ISO document providing the different measurement techniques validated for nanomaterial characterization was published [131]. Table 2 gives an overview of methods recommended for the characterization of physicochemical parameters, based on official guidelines and relevant literature of the field. This table also highlights ISO standards when existing for the considered methods and notices the availability of marketed instruments for a routine evaluation of the corresponding parameter. 


\begin{tabular}{|c|c|c|c|c|}
\hline Property & Method & Measurand & Advantages & Drawbacks \\
\hline \multirow{6}{*}{$\begin{array}{c}\text { Size } \\
{[103,105,106,110,130,131,133,135]}\end{array}$} & $\begin{array}{l}\text { Dynamic Light Scattering } \\
\qquad \text { (DLS) } * \neq\end{array}$ & $\begin{array}{l}\text { Hydrodynamic } \\
\text { diameter }\end{array}$ & Easy handling, low cost, rapid & $\begin{array}{l}\text { Not appropriate for multimodal } \\
\text { dispersions, low resolution, not } \\
\text { adapted to non-spherical NPs }\end{array}$ \\
\hline & $\begin{array}{l}\text { Particle tracking analysis } \\
\qquad(\text { PTA })^{*} \ddagger\end{array}$ & $\begin{array}{l}\text { Hydrodynamic } \\
\text { diameter }\end{array}$ & $\begin{array}{l}\text { Easy handling, low cost, rapid, } \\
\text { particle by particle }\end{array}$ & $\begin{array}{l}\text { More optimization than DLS, } \\
\text { resolution limited for very small } \\
\text { particles, not adapted to non- } \\
\text { spherical NPs }\end{array}$ \\
\hline & $\begin{array}{l}\text { Tunable Resistive Pulse } \\
\text { sensing (TRPS) *+ }\end{array}$ & Raw diameter & $\begin{array}{l}\text { Easy Handling, low cost, rapid, } \\
\text { particle by particle }\end{array}$ & $\begin{array}{c}\text { Not adapted to small particles } \\
(<40 \mathrm{~nm}) \text {, not adapted to non- } \\
\text { spherical NPs }\end{array}$ \\
\hline & $\begin{array}{c}\text { Differential centrifugal } \\
\text { sedimentation }(D C S) * \neq\end{array}$ & $\begin{array}{l}\text { Hydrodynamic } \\
\text { diameter }\end{array}$ & $\begin{array}{l}\text { Easy handling, separative, high } \\
\text { resolution }\end{array}$ & $\begin{array}{l}\text { Long for low density particles, not } \\
\text { adapted to non-spherical NPs }\end{array}$ \\
\hline & $\begin{array}{l}\text { Field Flow Fractionation } \\
\qquad \text { (FFF) coupled to } \\
\text { detector (Multi-angle LS, } \\
\text { DLS)** }\end{array}$ & $\begin{array}{l}\text { Hydrodynamic } \\
\text { diameter }\end{array}$ & $\begin{array}{l}\text { Separative, high resolution, } \\
\text { automatable, shape discriminant }\end{array}$ & $\begin{array}{l}\text { Condition, optimization, calibration } \\
\text { required, biased by large particles, } \\
\text { expertise needed }\end{array}$ \\
\hline & $\begin{array}{c}\text { Electron microscopy } \\
\text { (EM: SEM, TEM, Cryo- } \\
\text { TEM) }{ }^{* *} \ddagger\end{array}$ & Core diameter & $\begin{array}{l}\text { Direct visualization, shape } \\
\text { information, high resolution }\end{array}$ & $\begin{array}{l}\text { Labour intensive, low throughput, } \\
\text { dried sample, low density atoms less } \\
\text { sensitive, possible artifacts }\end{array}$ \\
\hline
\end{tabular}




\begin{tabular}{|c|c|c|c|c|}
\hline \multirow{6}{*}{$\begin{array}{l}\text { Size distribution } \\
{[103,105,106,110,130,131,133,135]}\end{array}$} & DLS * $\ddagger$ & Polydispersity index & $\begin{array}{c}\text { Gives a brief idea of the } \\
\text { polydispersity }\end{array}$ & $\begin{array}{c}\text { Small particles hidden by larger ones, } \\
\text { not adapted for multimodal } \\
\text { dispersions }\end{array}$ \\
\hline & PTA * $\ddagger$ & Size of populations & Particle by particle & Size resolution limited \\
\hline & TRPS $*+$ & Size of populations & Particle by particle & Not adapted to small particles \\
\hline & DCS * $\ddagger$ & Size of populations & Separative & $\begin{array}{l}\text { Difficult rotation velocity optimal for } \\
\text { multimodal samples }\end{array}$ \\
\hline & $\begin{array}{l}\text { FFF coupled to detector } \\
\text { (DLS, MALS) }{ }^{* *}\end{array}$ & Size of populations & Separative, high resolution & $\begin{array}{c}\text { Biased by large particles, expertise } \\
\text { needed }\end{array}$ \\
\hline & Electron microscopy $* * \ddagger$ & Size of populations & $\begin{array}{l}\text { High resolution, particle by } \\
\text { particle, visualization }\end{array}$ & Low throughput \\
\hline \multirow[t]{2}{*}{ Morphology } & Electron microscopy $* * \ddagger$ & Morphology & $\begin{array}{l}\text { Direct visualization, } \\
\text { general shape (sphere, rod, } \\
\text { complex shape), plain or core- } \\
\text { shell }\end{array}$ & $\begin{array}{l}\text { Expertise needed, low throughput, } \\
\text { low density atoms less sensitive, } \\
\text { possible artifacts }\end{array}$ \\
\hline & $\begin{array}{l}\text { X-ray diffraction (SAXS, } \\
\text { WAXS) }{ }^{* *} \ddagger\end{array}$ & Structural information & $\begin{array}{c}\text { Very sensitive, } \\
\text { supramolecular organization }\end{array}$ & $\begin{array}{l}\text { High expertise needed, not direct } \\
\text { access to shape }\end{array}$ \\
\hline
\end{tabular}




\begin{tabular}{|c|c|c|c|c|}
\hline & $\begin{array}{c}\text { Atomic Force } \\
\text { Microscopy }(\mathrm{AFM}) * *\end{array}$ & Topography & High resolution & $\begin{array}{l}\text { Expertise needed, lateral resolution } \\
\text { limited, not direct access to shape }\end{array}$ \\
\hline \multirow{4}{*}{$\begin{array}{l}\text { Surface charge } \\
\text { [103,105,106,110,130,131] }\end{array}$} & $\begin{array}{l}\text { Electrophoretic light } \\
\text { Scattering }(E L S) * \ddagger\end{array}$ & Zeta potential & Easy handling, low cost, rapid & $\begin{array}{c}\text { Not appropriate for multimodal } \\
\text { dispersions, highly dependent on } \\
\text { conditions (conductivity, pH, solvent), } \\
\text { apparent value }\end{array}$ \\
\hline & $\begin{array}{l}\text { Zeta Particle tracking } \\
\text { analysis * }\end{array}$ & Zeta Potential & $\begin{array}{c}\text { Easy handling, low cost, rapid, } \\
\text { particle by particle }\end{array}$ & $\begin{array}{l}\text { Resolution limited for very small } \\
\text { particles, apparent value }\end{array}$ \\
\hline & TRPS * + & Zeta Potential & $\begin{array}{c}\text { Easy handling, low cost, rapid, } \\
\text { particle by particle }\end{array}$ & $\begin{array}{l}\text { Not adapted to small particles ( }<40 \\
\qquad \mathrm{~nm}) \text {, apparent value }\end{array}$ \\
\hline & $\begin{array}{c}\text { Electroacoustic } \\
\text { spectroscopy * } \neq\end{array}$ & Zeta Potential & Adapted to concentrated samples & $\begin{array}{l}\text { Complex model, non-trivial sample } \\
\text { information required, apparent value }\end{array}$ \\
\hline \multirow[t]{3}{*}{$\begin{array}{l}\text { Surface chemistry } \\
{[103-105,110,112,130,131,156-160]}\end{array}$} & $\begin{array}{c}\text { X-ray Photoelectron } \\
\text { Spectroscopy (XPS) }{ }^{* *} \ddagger\end{array}$ & Surface composition & $\begin{array}{l}\text { Semi quantitative, chemical } \\
\text { analysis }\end{array}$ & $\begin{array}{c}\text { Dried sample, artifacts, outer layer } \\
\text { information (10 } \mathrm{nm} \text { depth), expertise } \\
\text { needed }\end{array}$ \\
\hline & $\begin{array}{c}\text { Secondary lon Mass } \\
\text { Spectroscopy (SIMS) ** } \\
\ddagger\end{array}$ & Surface composition & $\begin{array}{l}\text { 3D resolution, surface and inner } \\
\text { component analysis, high } \\
\text { sensitivity }\end{array}$ & $\begin{array}{l}\text { Expertise, dried sample, harsh } \\
\text { conditions may modify NPs }\end{array}$ \\
\hline & NMR * & $\begin{array}{l}\text { Amount of grafted } \\
\text { macromolecule }\end{array}$ & High sensitivity, automatable & $\begin{array}{l}\text { Deuterated medium needed, no } \\
\text { information about the conformation }\end{array}$ \\
\hline
\end{tabular}




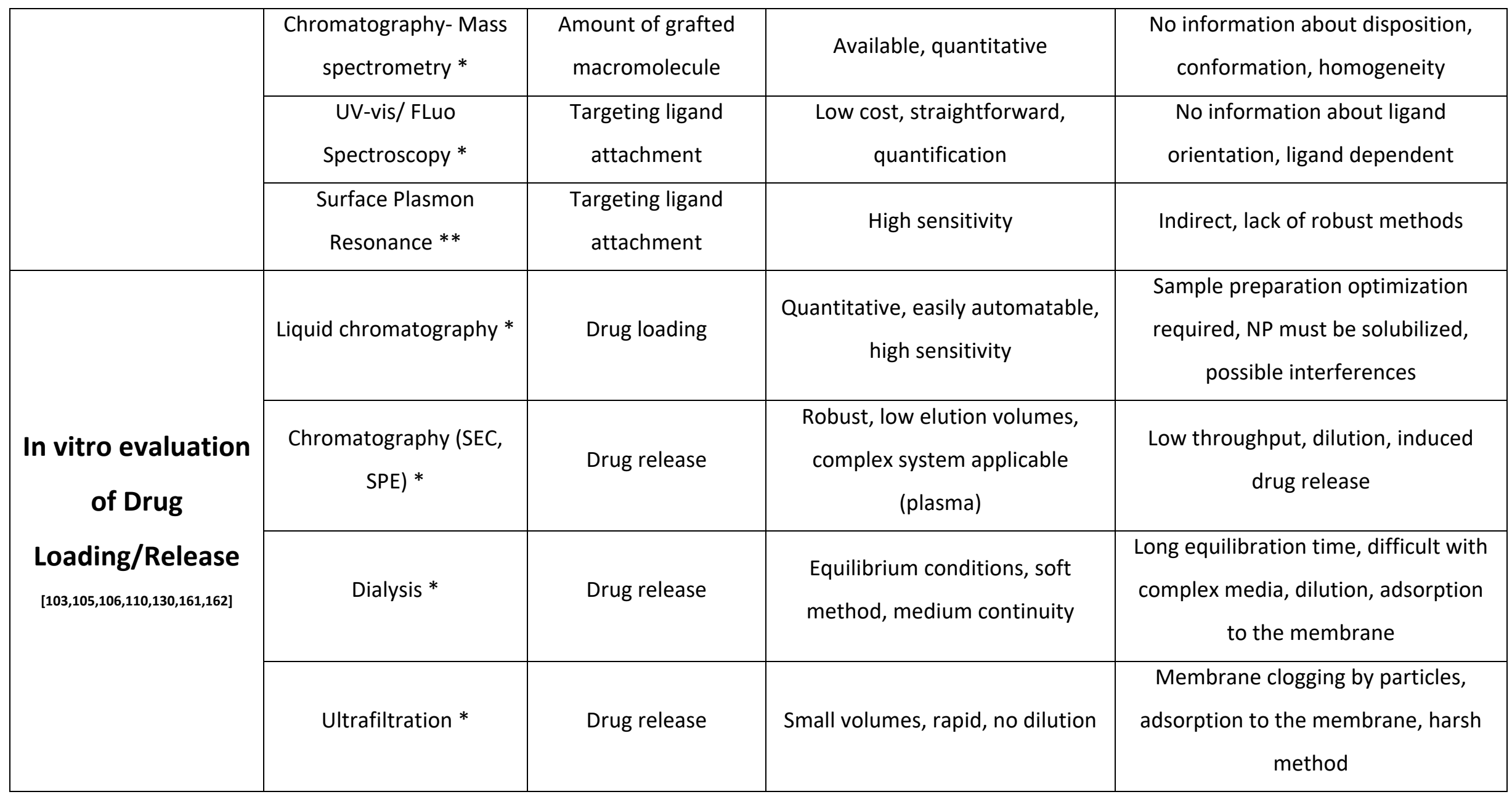

Table 2: Main methods used for current NMs physicochemical characterization and applied to elucidate their synthetic identity. Advantages and drawbacks. *Methods for which affordable instruments and batch measurements are available; ** Methods mostly applied in research laboratories; ¥ ISO Standard note available; † ISO standard note in preparation. 
First and foremost, size is a critical parameter of a nanomaterial for its in vivo fate, notably playing a role in the EPR (Enhanced Permeability and Retention) effect and modulating interactions with biological entities [37]. In practice, for size and size distribution measurement, dynamic light scattering (DLS) is the batch method by excellence due to its accessibility, low cost, easy handling and being described in an ISO standard [132]. All mentioned methods accessible via marketed instruments are accurate to determine size of monomodal dispersions. However, caution should be taken for an application to the characterization of dispersions with a multimodal size distribution [133-135]. For the evaluation of size distribution, a better resolution is accessible with methods such as tunable resistive pulse sensing (TRPS), particle tracking analysis (PTA) or including a separative coupling (differential centrifugal sedimentation (DCS), field-flow-fractionation - multi-angle light scattering DLS (FFF-MALS-DLS)). They are now available for routine analysis and should be more systematically used to demonstrate the homogeneity of size distribution prior to deal with DLS. It is now recommended to cross a batch size measurement such as DLS with another technique based on particle-by-particle measurement (TRPS, PTA) [119-121,135]. Application of these methods is expending since the recent market introduction of these instruments [137-140] and ISO standards published yet $[141,142]$.

Electron microscopy (EM) is suggested to be used to reinforce the value of size obtained by other methods and to obtain additional information on the sample, such as morphology, which is hardly obtained by any other method today. This method is not used in routine yet, being labor-intensive and rather unsuitable at a high throughput. However, efforts for its automation are ongoing as acknowledged by the development of systems for high throughput EM analysis either by automated sampling [143] or high throughput image analysis [144]. Such improvements for a better efficiency of EM have already been seen in the field of virus detection [145-147]. The development of a facilitated access and use of EM is even eagerly awaited since the arrival of diversified nanosystems for which EM is the only way to evaluate a core size and define the morphology (stars, cubes, hexagons, rods) [148150]. Shape and morphology of a nanomaterial influence its blood circulation (margination effect [151]) and interactions with cells $[152,153]$ compared with spherical counterparts. Although electron microscopy is the only method that can provide a direct evaluation of the size of nanomedicines, it is performed on dried samples. This is in contrast with other methods which offer size measurement in aqueous conditions that are closer systems compared with biological environments. So far, size measurements were qualified for a measure in a very simple matrix (purified aqueous samples), which gives information on the pristine nanomaterial. Methods for a pertinent evaluation of NMs size in biological medium (plasma, interstitial fluids) are under development, they are mentioned in the last part of this review. 
Then, the surface charge influences the interactions with proteins and cells [154]. This is commonly evaluated through the evaluation of an apparent zeta potential, generally performed with the same apparatus as used for size measurement. The duality of commercialized apparatus allows either a simultaneous measurement of size and charge (TRPS), or a possibility to assess both using different working modes included in the same instrument (electrophoretic light scattering (ELS)). Zeta potential is highly dependent on the analysis conditions (dispersion medium, system parameters), that is why only an apparent zeta potential can be determined if no correction of surface conductivity is applied, which is mainly the case. It is noteworthy that efforts about standardization of such methods are being made to ensure a qualified measure with robust protocols $[118,155,156]$.

Surface chemistry and architecture have been shown to be very important to control protein adsorption in vivo, influencing interactions with cell and even biocompatibility of the nanocarrier $[119,120]$. The control of a reproducible density of grafting is very challenging. As size measurement cannot ensure this parameter, it is acknowledged that more characterization methods are needed on this purpose $[26,103,106,112,157]$. So far, chromatographic methods are used in destructive conditions to do so $[130,158,159]$. A method investigating the 3D structure of NMs surface providing information on its chemical nature is the Secondary lon Mass Spectrometry (SIMS) $[159,160]$. The accessibility of such an instrument is nevertheless limited and it does not provide information about the architecture of the NM surface. When targeting moieties are attached to the surface, a quantitation of these moieties is required but only indirect methods to check their orientation are available today [22] and does not allow a clear characterization of their spatial arrangement.

For systems designed as drug carriers, drug loading and release are commonly assessed in vitro whereas bias still can hamper the true value of encapsulated and released drug amount. As excess amount of API could become toxic upon release, side effects could be observed. The phenomenon of burst release can also influence patient tolerability as well as efficacy. These parameters can be evaluated by quantitative dosage of the API. The problematic step is to achieve a proper separation between free and entrapped drug in physiological media. This is mainly done via chromatography techniques (SEC, SPE) as well as equilibrium methods (dialysis, ultrafiltration). Drug release can also be monitored by membrane diffusion methods such as dialysis [161,162].

Data included in table 2 highlights a lack of "ready to use" methodologies for several parameters (morphology, surface chemistry: grafting density, ligand attachment), thus pointing out a methodological bottleneck for the achievement of a straightforward full quality control of nanomedicines. Tremendous efforts are ongoing to fill out this gap [26]. A recent review by Gao et Lowry detailed the limitations of current methods and highlights the real need to improve robustness 
of nano-characterization [112]. References, standard materials, and standard operating procedures needed for the validation of methods of characterization are also under development for a common and more precise characterization. It must be mentioned that the NCL has considerably contributed to the development of characterization assays for nanomedicines, developing numerous protocols and becoming a reference laboratory for the characterization of nanomedicines entering clinical development [105].

Besides, the series of physicochemical parameters that are used to define the synthetic identity of nanomaterials composing NMs are probably not enough to ensure reproducible and expected results in biological media $[24,116,163]$. A recent study by Bertrand et al. [164] even emphasizes the fact that "the surface makeup of the particles, and not their dimension, is responsible for their removal from the bloodstream", highlighting the fact that interactions with blood component are mainly driven by local surface architecture and accessibility more than the size of the NM, yet the best characterized parameter. Hence, current assessed parameters depict nanomaterial properties at a relative "macroscopic level" in comparison with the sensitivity of biological systems. This notion is illustrated in figure 2 through examples of additional details perceived by biological systems. It is thus highly probable that "quiet changes" which may appear between batches are not detected during NMs control and certification whereas having a non-negligible impact for the in vivo behavior, including their biodistribution and safety. One of the challenges is to develop routine methods that reach biological systems' sensitivity and are able to detect the very small changes on NMs that are relevant for biological systems.

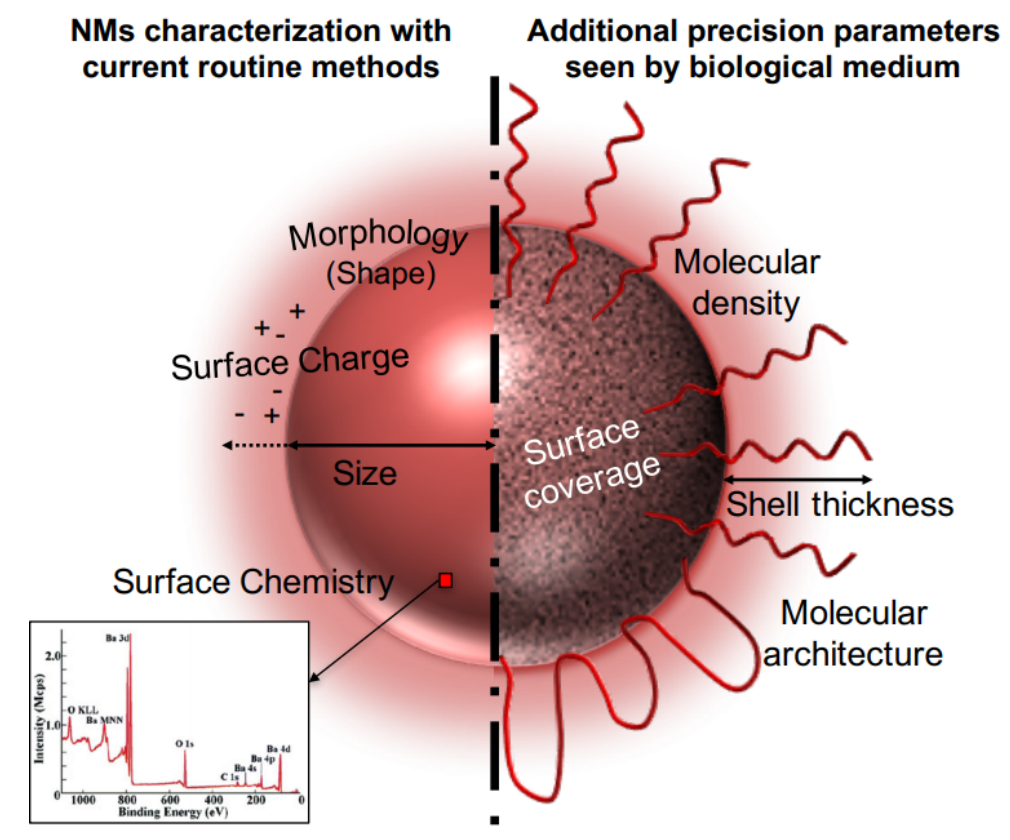

Figure 2: Illustration of the precision gap between current NMs' parameters determined in routine characterization versus details perceived by biological systems. 


\section{Acute characterization of nanomedicines for a warranted in vivo reproducibility}

\section{IV.1. Challenges for future characterization of NMs}

Current characterization methods of NMs allow the clear detection of modifications in size, morphology and surface charge of the synthetic identity. However, as mentioned in the first part of the review, biological systems are also highly sensitive to other NM characteristics. Although the size, surface composition and surface charge are well known characteristics that have been identified to influence the biological identity of NM, another important characteristic is the surface coverage that is still difficult to evaluate [165]. This includes the density of grafting of hydrophilic molecules grafted on nanoparticle surface, the molecular architecture of the chains and the homogeneity/heterogeneity of the coverage.

A joint effect of all synthetic parameters of the NM coupled to physiological conditions define the biological identity which is determinant for the in vivo fate of the NM [25]. Some computational studies tend to predict the behavior of a NM from its synthetic identity. This is the road to a more rational design and characterization of NMs for a reproducible action in vivo [166]. However, these correlations are not clearly established, and it appears risky to only control the currently evaluated physicochemical parameters to ensure a full in vivo reproducibility of a NM batch [167]. Recently, Lynch et al. stressed that current models used to predict biological outcomes from pristine parameters are not sufficient and need to be developed [89]. This pitfall can be further explained by the fact that the level of precision of current characterization methods applied in routine for NMs are much lower compared to biological systems sensitivity to detect changes in the synthetic identity of nanomaterials. So, there is an urgent need for methods assessing new parameters characterizing the synthetic identity of nanomedicines on a routine basis and at a much higher level of precision than already used methods $[26,103,157]$. These new parameters would appear as extensive information about NMs added to current commonly characterized properties. Moreover, current methods used for NMs characterization might not be representative of the real NM behavior in clinics. As an example, methodologies used to follow NMs once in contact with biological elements (e.g. cells, tissue) use markers that make the NM visible. However, these tracers change the actual identity and properties of the NM to which they are associated, thus possibly modifying the interaction with biological elements [89]. Thus, the methods to study the biological identity and activity of NMs have also to be improved. 


\section{IV.2. Neo-characterization of NMs introducing new methods or new parameters to investigate}

\section{IV.2.1. Assessing the synthetic identity of NMs}

As seen in the previous part, the interaction for antibody-antigen recognition might be dependent on a series a five amino-acid in a certain conformation. Compared to the current control of the grafting of targeting antibodies, it is impossible to tell if the orientation is optimal for a possible interaction. Some methods are developed on this purpose and try to map the accessible conjugates on the NMs. Among them, one uses 2D fluorescence difference spectroscopy to directly detect the attachment of ligand molecules to a nanoparticle surface [168]. In the same idea, an epitope mapping has been established by Dawson and coworkers using immunogold labelling (Fig. 3D) [169,170]. This method can be used for assessing targeting attachment success as well as orientation of grafted antibodies.

As highlighted earlier, methods for evaluating macromolecular grafting on NPs surface are lacking. Recently, Green Fluorescent Protein was used as a probe to measure PEG grafting efficacy on silica NPs. This was proofed to be efficient in elucidating a proper PEG grafting at a molecular level [171]. Also, Immunoelectron microscopy has been proposed to resolve the macromolecular shell around NPs by electron microscopy, task which is hardly feasible with conventional EM [172]. Although requiring the use of antibodies directed to the macromolecular shell, this approach could be interesting along with the improvement of EM high throughput mentioned earlier [143,144]. All these methods tend to fix the question of the uniformity and distribution of the surface moieties (e.g., PEG, peptides, aptamers) grafted on the NM surface. The burgeoning of methods comes as a response to a very important parameter that has been signaled as critical for a progress in NM characterization and understanding $[119,130]$.

\section{IV.2.2. Assessing the biological identity of NMs}

Finally, another way to test the nanomaterial directly for certain interactions is to directly deal with in vitro tests applicable routinely. There is a lack of applicable methods at a high throughput allowing a rapid testing of produced batch that hamper the control of their interactions with biological medias [117]. For example, the strong impact of protein adsorption on the NM's fate after intravenous injection is remarkably overlooked during routine characterization although deeply studied in research laboratories [173]. One of the main drawbacks is the demanding preparation required when working with biological elements, added to the high cost associated to bio-reagents (antibodies, plasma, proteins). An effort is needed in order to design in vitro methods that would reduce these drawbacks allowing them to be part of the common battery of tests performed on a batch of nanomedicine. 
At first, the determination of the protein corona formed around NPs after contact with plasma proteins constitute one of the most important tests performed in research to study the biological identity of NMs that is highly sensitive to the physicochemical identity of the NMs. This study is commonly made by LC-MS-MS and allows an identification of the protein adsorbed on NMs $[35,36,44,45]$. As performed in a relevant biological media, it is one of the most pertinent assays today for mimicking the biological identity of NMs. For a routine use, this method suffers from a lack of standardization especially because of the numerous variables of incubation conditions (temperature, dynamic/static, plasma source) and sample preparation steps (protein desorption, separation) which currently limit a universal evaluation of the protein corona $[174,175]$. This method also requires a specific equipment and a heavy data treatment. Moreover, the interpretation of the mass of data generated by this study is still not complete as the role of the different proteins found in the corona are not clearly established yet. The way to interpret the data has also been questioned due to the high averaging of proteins adsorbed obtained from millions of nanoparticles, rather than a particle-by-particle corona analysis [176]. A recent study using stochastic optical reconstruction microscopy (STORM) confirmed this heterogeneity in adsorption pattern between nanoparticles. This super resolution microscopy is presented as a new tool for protein corona in situ and dynamic study, that could be very relevant for correlation of NMs interactions with cells for example [177].

Another approach is developed for a rapid screening of NMs interactions with biological systems. Namely, Kuruvila et al. developed a method called SUSTU (SUrface proteo- mics, Safety, Targeting, Uptake) [178]. This method allows the study of the protein corona external surface that could be used to assess the in vivo behavior reproducibility of the NM. This method, while being still demanding experimentally, is proposed as a tool for NM prototyping in an integrated platform (Fig. 3A). Another group develops a screening method to study interactions of proteins with different NPs using fluorophore molecules affine to hydrophobic regions. They monitored the fluorescence in presence of different NP-Protein couples and could make assumption on adsorption behaviors thanks to the changes in fluorescence intensity (cf Fig. 3C). Developed in a 96-well format, this method can be considered as a possible candidate for NP-protein interactions routine screening [179].

To study more precisely the interaction on NMs with proteins and small molecules, Riviere's group developed a Biological Surface Adsorption Index (BSAI) in 2010. This model uses small molecules to probe the NM surface (Fig. 3B) [180]. By modelling the adsorption behavior of these probes, they could predict the adsorption of small molecules onto different nanomaterials [181]. The amount of adsorbed probes onto NMs was determined by gas chromatography coupled to mass spectrometry (GC-MS), allowing a high throughput analysis. The authors have thus defined an index that could be used to characterize NMs surfaces and predict their adsorption behavior, giving possible correlations of 
biodistribution and membrane interactions. Along with the current difficulties encountered by predictive models from physicochemical parameters, such methods introducing bio-elements like proteins might be a solution for an access to new information. They are sensitive to the steric hindrance found at the nanoparticle surface created by the molecular architecture of the macromolecules grafted on the nanoparticle surface.

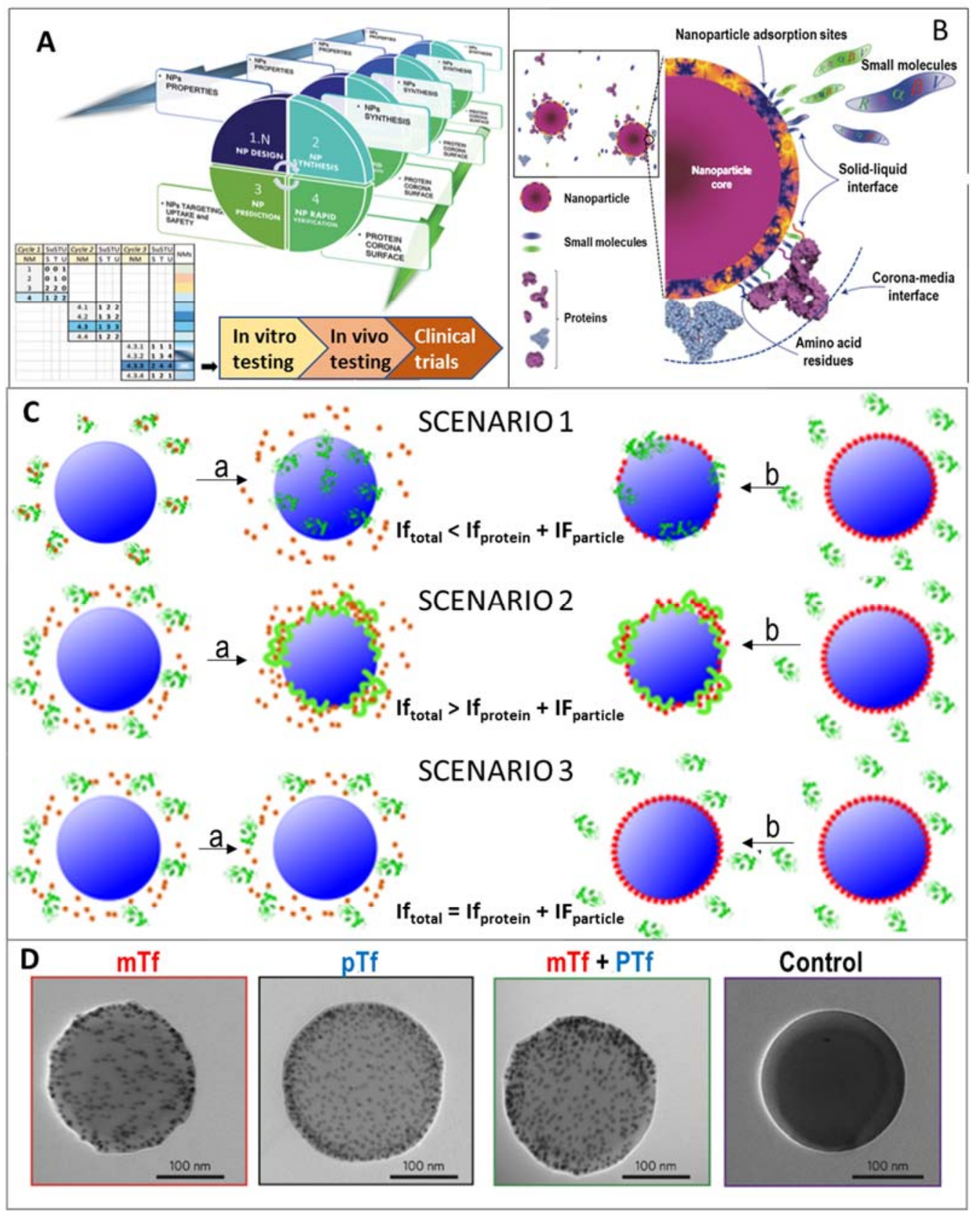

Figure 3: Candidate methods for a new routine characterization of NMs. A: Principle of the SUSTU integrated platform. The figure represents the concept of rapid screening of NMs as proposed by Kuruvilla et al. [178]. It comprises four steps from the NM design, synthesis, prediction and verification through the SUSTU analysis, evaluating the proteins at the external surface of the NM. This procedure allows for a prototyping of different system in order to select 
the best NM to be used for further development. B: Illustration of the BSAI index determination. Tested NMs are exposed to small model molecules. Adsorption of these molecules gives information about NM surface and possible interactions with biomolecules in vivo. C: Fluorescence scenarios for NPs adsorption characterization. Depending on the interaction between protein and NM, the change of fluorescence intensity (If) is monitored with a dye affine for hydrophobic surfaces. It allows to discriminate behavior of adsorption without rearrangement of the protein (scenario 1), with rearrangement and exposure of hydrophobic regions (scenario 2) or no adsorption (scenario 3). D: Epitope mapping for ligand attachment characterization. TEM images representing the mapping of Transferrin (Tf) coated at the surface of a NP. Gold labelling antibodies against Tf were used for the mapping by TEM imaging. mTf: monoclonal antibody directed against an epitope proximate to Tf receptor binding region. pTf: polyclonal antibody against Tf. ((A) was reproduced from [178] with permission of the Royal Society of chemistry, (B) was reprinted from [180] and (D) from [169] with permission from Macmillan Publishers Ltd, copyright (2010), (C) was reproduced from [179]).

A less sensible but more straightforward way to study the reproducibility of interactions between plasma proteins and NMs would be the measurement of size change occurring once both are in contact. EU-NCL proposed a FFF-MALS-DLS method for the batch to batch testing of plasma protein adsorption onto NMs [110]. Indeed, a reproducible elution profile could be the proof of a controlled interaction. With this method, the modification of size provided by proteins adsorption is measured. However, no indication about the composition of the protein corona is provided. Along the same lines, a recent method using Single Particle Extinction and Scattering (SPES) was developed to follow the NM size upon incubation in serum [182]. This optical method uses light scattering on a particle-by-particle analysis to study NMs distribution in presence of biological fluids. This prototype considers two parameters for size measurements, namely the polarizability and the optical thickness of the NM. This study about in situ size measurement has also been done using TRPS $[139,183]$. These methods could complement current batch size measurements provided by DLS, all providing a biological relevance added to the pristine NM diameter measured so far.

Finally, complement system activation assays give indications on possible risks of complement activation related pseudo allergy (CARPA) $[184,185]$. An in vitro assessment of complement activation could be required by health authorities prior to batch release. We have recently proposed the establishment of an indicator of complement $\mathrm{C} 3$ activation $\left(\mathrm{C} \mathrm{A}_{50}\right)$ for the characterization of NMs' tendency to activate the complement system [186]. The value of this indicator differs depending on the nanoparticle's surface characteristics and is sensitive to the architecture of macromolecules 
grafted on the nanoparticle surface. The method for the determination of this parameter is based on 2D-electrophoresis and was optimized for a high-throughput sample analysis [186].

\section{Conclusion}

Facing the current hurdles of translation of NMs, a smarter characterization of nanomaterials is urgently needed. Regulatory agencies have worked on the gap between conventional drug and nanomedicines establishing new guidelines, defining properties specific to nanomaterials. These guidelines for NM batch release focus on the description of intrinsic properties of nanomaterials composing nanomedicines, whereas it is pointed out that the biological identity formed in vivo is the one driving the fate of the NM. Even for these key physicochemical parameters that seems to be the best controlled until now, many improvements are needed to achieve a more precise and robust investigation. However, the sensitivity found in biological system does not allow for such a "macrocharacterization" of nanomaterials as it is the case now. An effort on method development, accessibility, automation, relevance and sensitivity is upcoming. This passes by the improvement of certain current methods, the establishment of new ones, and the introduction of biological components in routine tests. A better control of NM batches is expected to come from these new methods and some with biological components may be relevant to detect critical points for in vivo reproducibility and strengthen the confidence in NMs batches tested in clinical trials.

Declarations of interest: none.

\section{Acknowledgments}

This work was supported by BPI-France, project NICE. 


\section{Abbreviations}

AFM: Atomic force microscopy API: Active pharmaceutical ingredient BSAI: Biological Surface Adsorption Index CARPA: Complement activation related pseudo allergy CRO: Contract research organization DCS: Differential centrifugal sedimentation

DLS: Dynamic light scattering ELS: Electrophoretic light scattering EM: Electron microscopy EMA: European medicine agency EPR: Enhanced permeation and retention EUNCL: European Nanomedicine Characterization Laboratory FDA: Food and drug administration FFF: Field flow fractionation GC-MS: Gas chromatography - mass spectrometry ISO: International Standard Organization LC-MS: Liquid chromatography-mass spectrometry MALS: Multi-angle light scattering NC: Nanocarrier NCL: Nanotechnology Characterization Laboratory $\mathrm{NIH}$ : National Institute of Health N. meningitidis: Neisseria meningitidis NM: Nanomedicine NMR: Nuclear magnetic resonance NP: Nanoparticle OECD: Organization for Economic Co-operation and Development PD: Pharmacodynamics PEG: Polyethylene glycol PK: Pharmacokinetics PTA: Particle tracking analysis SAXS: Small angle X-ray scattering SEC: Size exclusion chromatography SEM: Scanning electron microscopy SIMS: Secondary ion mass spectrometry SPE: Solid phase extraction STORM: Stochastic optical reconstruction microscopy SUSTU: SUrface proteo- mics, Safety, Targeting, Uptake TEM: Transmission electron microscopy TRPS: Tunable resistive pulse sensing WAXS: Wide angle $X$-ray scattering 


\section{Bibliography}

[1] Sims, C. M., Hanna, S. K., Heller, D. A., Horoszko, C. P., Johnson, M. E., Montoro Bustos, A. R., Reipa, V., Riley, K. R. \& Nelson, B. C. Redox-active nanomaterials for nanomedicine applications. Nanoscale 9, 15226-15251 (2017).

[2] Pottier, A., Borghi, E. \& Levy, L. The future of nanosized radiation enhancers. The British Journal of Radiology 88, 20150171 (2015).

[3] Thiesen, B. \& Jordan, A. Clinical applications of magnetic nanoparticles for hyperthermia. International Journal of Hyperthermia 24, 467-474 (2008).

[4] Leem Comité Biotech - Applications des nanotechnologies à la médecine. https://www.etp-nanomedicine.eu/public/press-documents/publications/publicdocuments/bionest-partners-2014-nanomedicine-study-leem/Rapport final version definitive.pdf (2013). Consulted on August 2017

[5] Ventola, C. L. The nanomedicine revolution: part 1: emerging concepts. Pharmacy and Therapeutics 37, 512 (2012).

[6] Wang, Y.-F., Liu, L., Xue, X., \& Liang, X.-J. Nanoparticle-based drug delivery systems: What can they really do in vivo? F1000Research 6, 681 (2017).

[7] Sainz, V., Conniot, J., Matos, A. I., Peres, C., Zupanǒiǒ, E., Moura, L., Silva, L. C., Florindo, H. F. \& Gaspar, R. S. Regulatory aspects on nanomedicines. Biochemical and Biophysical Research Communications 468, 504-510 (2015).

[8] Tinkle, S., McNeil, S. E., Mühlebach, S., Bawa, R., Borchard, G., Barenholz, Y. C., Tamarkin, L. \& Desai, N. Nanomedicines: addressing the scientific and regulatory gap: Nanomedicines. Annals of the New York Academy of Sciences 1313, 35-56 (2014).

[9] Weissig, V., Pettinger, T. \& Murdock, N. Nanopharmaceuticals (part 1): products on the market. International Journal of Nanomedicine 4357 (2014).

[10] Ragelle, H., Danhier, F., Préat, V., Langer, R. \& Anderson, D. G. Nanoparticle-based drug delivery systems: a commercial and regulatory outlook as the field matures. Expert Opinion on Drug Delivery 14, 851-864 (2017).

[11] Landesman-Milo, D. \& Peer, D. Transforming Nanomedicines From Lab Scale Production to Novel Clinical Modality. Bioconjugate Chemistry 27, 855-862 (2016).

[12] Peer, D., Cornier, J., Van de Voorde, M., Cornier, J., Owen, A., Kwade, A. \& Van de Voorde, M. in Pharmaceutical Nanotechnology: Innovation and Production 735-742 (Wiley-VCH Verlag GmbH \& Co. KGaA, 2017).

[13] P, B. Nanomedicines can Offer Improved Therapeutic Efficacy through Various Parenteral Routes of Administration. Journal of Nanomedicine \& Nanotechnology 07, (2016).

[14] Mansour, H. \& Park, C.-W. in The Clinical Nanomedicine Handbook 321-338 (CRC Press, 2013).

[15] Scomparin, A., Polyak, D., Krivitsky, A. \& Satchi-Fainaro, R. Achieving successful delivery of oligonucleotides - From physico-chemical characterization to in vivo evaluation. Biotechnology Advances 33, 1294-1309 (2015).

[16] Neagu, M., Piperigkou, Z., Karamanou, K., Engin, A. B., Docea, A. O., Constantin, C., Negrei, C., Nikitovic, D. \& Tsatsakis, A. Protein bio-corona: critical issue in immune nanotoxicology. Archives of Toxicology 91, 1031-1048 (2017).

[17] Gunawan, C., Lim, M., Marquis, C. P. \& Amal, R. Nanoparticle-protein corona complexes govern the biological fates and functions of nanoparticles. J. Mater. Chem. $B$ 2, 2060-2083 (2014). 
[18] Alexis, F., Pridgen, E., Molnar, L. K. \& Farokhzad, O. C. Factors Affecting the Clearance and Biodistribution of Polymeric Nanoparticles. Molecular Pharmaceutics 5, 505-515 (2008).

[19] Peracchia, M. T., Desmaële, D., Vauthier, C., Labarre, D., Fattal, E., d'Angelo, J. \& Couvreur, P. in Targeting of Drugs 6: Strategies for Stealth Therapeutic Systems (eds. Gregoriadis, G. \& McCormack, B.) 225-239 (Springer US, 1998).

[20] Verrecchia, T., Spenlehauer, G., Bazile, D. V., Murry-Brelier, A., Archimbaud, Y. \& Veillard, M. Non-stealth (poly (lactic acid/albumin)) and stealth (poly (lactic acidpolyethylene glycol)) nanoparticles as injectable drug carriers. Journal of Controlled Release 36, 49-61 (1995).

[21] Bazile, D., Prud'homme, C., Bassoullet, M.-T., Marlard, M., Spenlehauer, G. \& Veillard, M. Stealth Me. PEG-PLA nanoparticles avoid uptake by the mononuclear phagocytes system. Journal of pharmaceutical sciences 84, 493-498 (1995).

[22] Gref, R., Domb, A., Quellec, P., Blunk, T., Müller, R. H., Verbavatz, J. M. \& Langer, R. The controlled intravenous delivery of drugs using PEG-coated sterically stabilized nanospheres. Advanced Drug Delivery Reviews 16, 215-233 (1995).

[23] Passirani, C., Barratt, G., Devissaguet, J.-P. \& Labarre, D. Interactions of nanoparticles bearing heparin or dextran covalently bound to poly (methyl methacrylate) with the complement system. Life sciences 62, 775-785 (1998).

[24] Polo, E., Castagnola, V., Dawson, K. A., Cornier, J., Owen, A., Kwade, A. \& Van de Voorde, M. in Pharmaceutical Nanotechnology: Innovation and Production 63-80 (WileyVCH Verlag GmbH \& Co. KGaA, 2017).

[25] Fadeel, B., Feliu, N., Vogt, C., Abdelmonem, A. M. \& Parak, W. J. Bridge over troubled waters: understanding the synthetic and biological identities of engineered nanomaterials: Bridging nanotoxicology and nanomedicine. Wiley Interdisciplinary Reviews: Nanomedicine and Nanobiotechnology 5, 111-129 (2013).

[26] Salvador Morales, C., Khorasani, A. A. \& Weaver, J. Closing the gap: accelerating the translational process in nanomedicine by proposing standardized characterization techniques. International Journal of Nanomedicine 5729 (2014).

[27] Wilhelm, S., Tavares, A. J., Dai, Q., Ohta, S., Audet, J., Dvorak, H. F. \& Chan, W. C. W. Analysis of nanoparticle delivery to tumours. Nature Reviews Materials 1, 16014 (2016).

[28] Schöttler, S., Landfester, K. \& Mailänder, V. Controlling the Stealth Effect of Nanocarriers through Understanding the Protein Corona. Angewandte Chemie International Edition 55, 8806-8815 (2016).

[29] Gatter, K. C., Brown, G., Trowbridge, I. S., Woolston, R. E. \& Mason, D. Y. Transferrin receptors in human tissues: their distribution and possible clinical relevance. Journal of Clinical Pathology 36, 539-545 (1983).

[30] Garcia-Garcia, E., Andrieux, K., Gil, S. \& Couvreur, P. Colloidal carriers and blood-brain barrier (BBB) translocation: A way to deliver drugs to the brain? International Journal of Pharmaceutics 298, 274-292 (2005).

[31] Walkey, C. D. \& Chan, W. C. W. Understanding and controlling the interaction of nanomaterials with proteins in a physiological environment. Chem. Soc. Rev. 41, 27802799 (2012).

[32] Foroozandeh, P. \& Aziz, A. A. Merging Worlds of Nanomaterials and Biological Environment: Factors Governing Protein Corona Formation on Nanoparticles and Its Biological Consequences. Nanoscale Research Letters 10, (2015). 
[33] Nguyen, V. H. \& Lee, B.-J. Protein corona: a new approach for nanomedicine design. International Journal of Nanomedicine Volume 12, 3137-3151 (2017).

[34] Kharazian, B., Hadipour, N. L. \& Ejtehadi, M. R. Understanding the nanoparticleprotein corona complexes using computational and experimental methods. The International Journal of Biochemistry \& Cell Biology 75, 162-174 (2016).

[35] Schäffler, M., Semmler-Behnke, M., Sarioglu, H., Takenaka, S., Wenk, A., Schleh, C., Hauck, S. M., Johnston, B. D. \& Kreyling, W. G. Serum protein identification and quantification of the corona of 5, 15 and $80 \mathrm{~nm}$ gold nanoparticles. Nanotechnology 24, 265103 (2013).

[36] Walkey, C. D., Olsen, J. B., Song, F., Liu, R., Guo, H., Olsen, D. W. H., Cohen, Y., Emili, A. \& Chan, W. C. W. Protein Corona Fingerprinting Predicts the Cellular Interaction of Gold and Silver Nanoparticles. ACS Nano 8, 2439-2455 (2014).

[37] Tenzer, S., Docter, D., Rosfa, S., Wlodarski, A., Kuharev, J., Rekik, A., Knauer, S. K., Bantz, C., Nawroth, T., Bier, C., Sirirattanapan, J., Mann, W., Treuel, L., Zellner, R., Maskos, M., Schild, H. \& Stauber, R. H. Nanoparticle Size Is a Critical Physicochemical Determinant of the Human Blood Plasma Corona: A Comprehensive Quantitative Proteomic Analysis. ACS Nano 5, 7155-7167 (2011).

[38] Lundqvist, M., Stigler, J., Elia, G., Lynch, I., Cedervall, T. \& Dawson, K. A. Nanoparticle size and surface properties determine the protein corona with possible implications for biological impacts. Proceedings of the National Academy of Sciences 105, 14265-14270 (2008).

[39] Clemments, A. M., Botella, P. \& Landry, C. C. Protein Adsorption From Biofluids on Silica Nanoparticles: Corona Analysis as a Function of Particle Diameter and Porosity. ACS Applied Materials \& Interfaces 7, 21682-21689 (2015).

[40] Gagner, J. E., Lopez, M. D., Dordick, J. S. \& Siegel, R. W. Effect of gold nanoparticle morphology on adsorbed protein structure and function. Biomaterials 32, 7241-7252 (2011).

[41] Saha, K., Rahimi, M., Yazdani, M., Kim, S. T., Moyano, D. F., Hou, S., Das, R., Mout, R., Rezaee, F., Mahmoudi, M. \& Rotello, V. M. Regulation of Macrophage Recognition through the Interplay of Nanoparticle Surface Functionality and Protein Corona. ACS Nano 10, 4421-4430 (2016).

[42] Lai, W., Wang, Q., Li, L., Hu, Z., Chen, J. \& Fang, Q. Interaction of gold and silver nanoparticles with human plasma: Analysis of protein corona reveals specific binding patterns. Colloids and Surfaces B: Biointerfaces 152, 317-325 (2017).

[43] Kurtz-Chalot, A., Villiers, C., Pourchez, J., Boudard, D., Martini, M., Marche, P. N., Cottier, M. \& Forest, V. Impact of silica nanoparticle surface chemistry on protein corona formation and consequential interactions with biological cells. Materials Science and Engineering: C 75, 16-24 (2017).

[44] Sakulkhu, U., Mahmoudi, M., Maurizi, L., Coullerez, G., Hofmann-Amtenbrink, M., Vries, M., Motazacker, M., Rezaee, F. \& Hofmann, H. Significance of surface charge and shell material of superparamagnetic iron oxide nanoparticle (SPION) based core/shell nanoparticles on the composition of the protein corona. Biomater. Sci. 3, 265-278 (2015).

[45] Vogt, C., Pernemalm, M., Kohonen, P., Laurent, S., Hultenby, K., Vahter, M., Lehtiö, J., Toprak, M. S. \& Fadeel, B. Proteomics Analysis Reveals Distinct Corona Composition on Magnetic Nanoparticles with Different Surface Coatings: Implications for Interactions with Primary Human Macrophages. PLOS ONE 10, e0129008 (2015). 
[46] Leroux, J.-C., Gravel, P., Balant, L., Volet, B., Anner, B. M., Allémann, E., Doelker, E. \& Gurny, R. Internalization of poly(D,L-1actic acid) nanoparticles by isolated human leukocytes and analysis of plasma proteins adsorbed onto the particles. Journal of Biomedical Materials Research 28, 471-481 (1994).

[47] Gref, R., Lück, M., Quellec, P., Marchand, M., Dellacherie, E., Harnisch, S., Blunk, T. \& Müller, R. . 'Stealth' corona-core nanoparticles surface modified by polyethylene glycol (PEG): influences of the corona (PEG chain length and surface density) and of the core composition on phagocytic uptake and plasma protein adsorption. Colloids and Surfaces B: Biointerfaces 18, 301-313 (2000).

[48] Peracchia, M. T., Harnisch, S., Pinto-Alphandary, H., Gulik, A., Dedieu, J. C., Desmaele, D., d'Angelo, J., Müller, R. H. \& Couvreur, P. Visualization of in vitro protein-rejecting properties of PEGylated stealth $^{\circledR}$ polycyanoacrylate nanoparticles. Biomaterials 20, 1269-1275 (1999).

[49] Lemarchand, C., Gref, R. \& Couvreur, P. Polysaccharide-decorated nanoparticles. European Journal of Pharmaceutics and Biopharmaceutics 58, 327-341 (2004).

[50] Labarre, D., Vauthier, C., Chauvierre, C., Petri, B., Muller, R. \& Chehimi, M. Interactions of blood proteins with poly(isobutylcyanoacrylate) nanoparticles decorated with a polysaccharidic brush. Biomaterials 26, 5075-5084 (2005).

[51] Müller, J., Bauer, K. N., Prozeller, D., Simon, J., Mailänder, V., Wurm, F. R., Winzen, S. \& Landfester, K. Coating nanoparticles with tunable surfactants facilitates control over the protein corona. Biomaterials 115, 1-8 (2017).

[52] Walkey, C. D., Olsen, J. B., Guo, H., Emili, A. \& Chan, W. C. W. Nanoparticle Size and Surface Chemistry Determine Serum Protein Adsorption and Macrophage Uptake. Journal of the American Chemical Society 134, 2139-2147 (2012).

[53] Pozzi, D., Colapicchioni, V., Caracciolo, G., Piovesana, S., Capriotti, A. L., Palchetti, S., De Grossi, S., Riccioli, A., Amenitsch, H. \& Laganà, A. Effect of polyethyleneglycol (PEG) chain length on the bio-nano-interactions between PEGylated lipid nanoparticles and biological fluids: from nanostructure to uptake in cancer cells. Nanoscale 6, 2782 (2014).

[54] Pozzi, D., Caracciolo, G., Capriotti, A. L., Cavaliere, C., La Barbera, G., Anchordoquy, T. J. \& Laganà, A. Surface chemistry and serum type both determine the nanoparticleprotein corona. Journal of Proteomics 119, 209-217 (2015).

[55] Aggarwal, P., Hall, J. B., McLeland, C. B., Dobrovolskaia, M. A. \& McNeil, S. E. Nanoparticle interaction with plasma proteins as it relates to particle biodistribution, biocompatibility and therapeutic efficacy. Advanced Drug Delivery Reviews 61, 428-437 (2009).

[56] Dobrovolskaia, M. A., Neun, B. W., Man, S., Ye, X., Hansen, M., Patri, A. K., Crist, R. M. \& McNeil, S. E. Protein corona composition does not accurately predict hematocompatibility of colloidal gold nanoparticles. Nanomedicine: Nanotechnology, Biology and Medicine 10, 1453-1463 (2014).

[57] Schöttler, S., Becker, G., Winzen, S., Steinbach, T., Mohr, K., Landfester, K., Mailänder, V. \& Wurm, F. R. Protein adsorption is required for stealth effect of poly(ethylene glycol)and poly(phosphoester)-coated nanocarriers. Nature Nanotechnology 11, 372-377 (2016).

[58] Thomas, S. N., van der Vlies, A. J., O’Neil, C. P., Reddy, S. T., Yu, S. S., Giorgio, T. D., Swartz, M. A. \& Hubbell, J. A. Engineering complement activation on polypropylene sulfide vaccine nanoparticles. Biomaterials 32, 2194-2203 (2011). 
[59] Salvador-Morales, C., Zhang, L., Langer, R. \& Farokhzad, O. C. Immunocompatibility properties of lipid-polymer hybrid nanoparticles with heterogeneous surface functional groups. Biomaterials 30, 2231-2240 (2009).

[60] Vonarbourg, A., Passirani, C., Saulnier, P. \& Benoit, J.-P. Parameters influencing the stealthiness of colloidal drug delivery systems. Biomaterials 27, 4356-4373 (2006).

[61] Peracchia, M. T., Vauthier, C., Passirani, C., Couvreur, P. \& Labarre, D. Complement consumption by poly(ethylene glycol) in different conformations chemically coupled to poly(isobutyl 2-cyanoacrylate) nanoparticles. Life Sciences 61, 749-761 (1997).

[62] Vittaz, M., Bazile, D., Spenlehauer, G., Verrecchia, T., Veillard, M., Puisieux, F. \& Labarre, D. Effect of PEO surface density on long-circulating PLA-PEO nanoparticles which are very low complement activators. Biomaterials 17, 1575-1581 (1996).

[63] Hamad, I., Al-Hanbali, O., Hunter, A. C., Rutt, K. J., Andresen, T. L. \& Moghimi, S. M. Distinct Polymer Architecture Mediates Switching of Complement Activation Pathways at the Nanosphere-Serum Interface: Implications for Stealth Nanoparticle Engineering. ACS Nano 4, 6629-6638 (2010).

[64] D'Addio, S. M., Saad, W., Ansell, S. M., Squiers, J. J., Adamson, D. H., Herrera-Alonso, M., Wohl, A. R., Hoye, T. R., Macosko, C. W., Mayer, L. D., Vauthier, C. \& Prud'homme, R. $\mathrm{K}$. Effects of block copolymer properties on nanocarrier protection from in vivo clearance. Journal of Controlled Release 162, 208-217 (2012).

[65] Chen, C. C. \& Borden, M. A. The role of poly(ethylene glycol) brush architecture in complement activation on targeted microbubble surfaces. Biomaterials 32, 6579-6587 (2011).

[66] Bertholon, I., Vauthier, C. \& Labarre, D. Complement Activation by Core-Shell Poly(isobutylcyanoacrylate)-Polysaccharide Nanoparticles: Influences of Surface Morphology, Length, and Type of Polysaccharide. Pharmaceutical Research 23, 13131323 (2006).

[67] Zandanel, C. \& Vauthier, C. Poly(isobutylcyanoacrylate) Nanoparticles Decorated with Chitosan: Effect of Conformation of Chitosan Chains at the Surface on Complement Activation Properties. Journal of Colloid Science and Biotechnology 1, 68-81 (2012).

[68] Labarre, D. The Interactions between Blood and Polymeric Nanoparticles Depend on the Nature and Structure of the Hydrogel Covering the Surface. Polymers 4, 986-996 (2012).

[69] Coty, J.-B., Eleamen Oliveira, E. \& Vauthier, C. Tuning complement activation and pathway through controlled molecular architecture of dextran chains in nanoparticle corona. International Journal of Pharmaceutics 532, 769-778 (2017).

[70] Yu, K., Lai, B. F. L., Foley, J. H., Krisinger, M. J., Conway, E. M. \& Kizhakkedathu, J. N. Modulation of Complement Activation and Amplification on Nanoparticle Surfaces by Glycopolymer Conformation and Chemistry. ACS Nano 8, 7687-7703 (2014).

[71] Ilinskaya, A. N. \& Dobrovolskaia, M. A. Nanoparticles and the blood coagulation system. Part I: benefits of nanotechnology. Nanomedicine 8, 773-784 (2013).

[72] Ilinskaya, A. N. \& Dobrovolskaia, M. A. Nanoparticles and the blood coagulation system. Part II: safety concerns. Nanomedicine 8, 969-981 (2013).

[73] Kumar Khanna, V. Targeted Delivery of Nanomedicines. ISRN Pharmacology 2012, 19 (2012).

[74] Gao, H., Yang, Z., Zhang, S., Cao, S., Shen, S., Pang, Z. \& Jiang, X. Ligand modified nanoparticles increases cell uptake, alters endocytosis and elevates glioma distribution and internalization. Scientific Reports 3, (2013). 
[75] Yao, V. J., D’Angelo, S., Butler, K. S., Theron, C., Smith, T. L., Marchiò, S., Gelovani, J. G., Sidman, R. L., Dobroff, A. S., Brinker, C. J., Bradbury, A. R. M., Arap, W. \& Pasqualini, R. Ligand-targeted theranostic nanomedicines against cancer. Journal of Controlled Release 240, 267-286 (2016).

[76] Hak, S., Cebulla, J., Huuse, E. M., Davies, C. de L., Mulder, W. J. M., Larsson, H. B. W. \& Haraldseth, $O$. Periodicity in tumor vasculature targeting kinetics of ligandfunctionalized nanoparticles studied by dynamic contrast enhanced magnetic resonance imaging and intravital microscopy. Angiogenesis 17, 93-107 (2014).

[77] Yameen, B., Choi, W. I., Vilos, C., Swami, A., Shi, J. \& Farokhzad, O. C. Insight into nanoparticle cellular uptake and intracellular targeting. Journal of Controlled Release 190, 485-499 (2014).

[78] Behzadi, S., Serpooshan, V., Tao, W., Hamaly, M. A., Alkawareek, M. Y., Dreaden, E. C., Brown, D., Alkilany, A. M., Farokhzad, O. C. \& Mahmoudi, M. Cellular uptake of nanoparticles: journey inside the cell. Chem. Soc. Rev. 46, 4218-4244 (2017).

[79] Hillaireau, H. in Polymer Nanoparticles for Nanomedicines: A Guide for their Design, Preparation and Development (eds. Vauthier, C. \& Ponchel, G.) 291-323 (Springer International Publishing, 2016).

[80] Hillaireau, H. \& Couvreur, P. Nanocarriers' entry into the cell: relevance to drug delivery. Cellular and Molecular Life Sciences 66, 2873-2896 (2009).

[81] Seo, S.-J., Chen, M., Wang, H., Kang, M. S., Leong, K. W. \& Kim, H.-W. Extra- and intracellular fate of nanocarriers under dynamic interactions with biology. Nano Today 14, 8499 (2017).

[82] Carnovale, C., Bryant, G., Shukla, R. \& Bansal, V. Size, shape and surface chemistry of nano-gold dictate its cellular interactions, uptake and toxicity. Progress in Materials Science 83, 152-190 (2016).

[83] Kang, J. H., Jang, W. Y. \& Ko, Y. T. The Effect of Surface Charges on the Cellular Uptake of Liposomes Investigated by Live Cell Imaging. Pharmaceutical Research 34, 704-717 (2017).

[84] Lira, M. C. B., Santos-Magalhães, N. S., Nicolas, V., Marsaud, V., Silva, M. P. C., Ponchel, G. \& Vauthier, C. Cytotoxicity and cellular uptake of newly synthesized fucoidan-coated nanoparticles. European Journal of Pharmaceutics and Biopharmaceutics 79, 162-170 (2011).

[85] Beck, M., Mandal, T., Buske, C. \& Lindén, M. Serum protein adsorption enhances active leukemia stem cell targeting of mesoporous silica nanoparticles. ACS Applied Materials \& Interfaces (2017).

[86] Barrán-Berdón, A. L., Pozzi, D., Caracciolo, G., Capriotti, A. L., Caruso, G., Cavaliere, C., Riccioli, A., Palchetti, S. \& Laganà, A. Time Evolution of Nanoparticle-Protein Corona in Human Plasma: Relevance for Targeted Drug Delivery. Langmuir 29, 6485-6494 (2013).

[87] Bigdeli, A., Palchetti, S., Pozzi, D., Hormozi-Nezhad, M. R., Baldelli Bombelli, F., Caracciolo, G. \& Mahmoudi, M. Exploring Cellular Interactions of Liposomes Using Protein Corona Fingerprints and Physicochemical Properties. ACS Nano 10, 3723-3737 (2016).

[88] Digiacomo, L., Cardarelli, F., Pozzi, D., Palchetti, S., Digman, M. A., Gratton, E., Capriotti, A. L., Mahmoudi, M. \& Caracciolo, G. An apolipoprotein-enriched biomolecular corona switches the cellular uptake mechanism and trafficking pathway of lipid nanoparticles. Nanoscale (2017). doi:10.1039/C7NR06437C 
[89] Lynch, I., Afantitis, A., Leonis, G., Melagraki, G. \& Valsami-Jones, E. in Advances in QSAR Modeling: Applications in Pharmaceutical, Chemical, Food, Agricultural and Environmental Sciences (ed. Roy, K.) 385-424 (Springer International Publishing, 2017).

[90] Caracciolo, G., Farokhzad, O. C. \& Mahmoudi, M. Biological Identity of Nanoparticles In Vivo: Clinical Implications of the Protein Corona. Trends in Biotechnology 35, 257-264 (2017).

[91] Snipstad, S., Hak, S., Baghirov, H., Sulheim, E., Mørch, Ý., Lélu, S., von Haartman, E., Bäck, M., Nilsson, K. P. R., Klymchenko, A. S., de Lange Davies, C. \& Åslund, A. K. O. Labeling nanoparticles: Dye leakage and altered cellular uptake: Labeling Nanoparticles with Dyes. Cytometry Part A 91, 760-766 (2017).

[92] Spinosa, M. R., Progida, C., Talà, A., Cogli, L., Alifano, P. \& Bucci, C. The Neisseria meningitidis Capsule Is Important for Intracellular Survival in Human Cells. Infection and Immunity 75, 3594-3603 (2007).

[93] Swartley, J. S., Marfin, A. A., Edupuganti, S., Liu, L.-J., Cieslak, P., Perkins, B., Wenger, J. D. \& Stephens, D. S. Capsule switching of Neisseria meningitidis. Proceedings of the National Academy of Sciences 94, 271-276 (1997).

[94] Huve, P. Comprendre et éviter la capture des nanoparticules de poly(acide-lactique) par le système des phagocytes mononucléaires - Thèse de doctorat (1994).

[95] Jennings, H. J. \& Lugowski, C. Immunochemistry of groups A, B, and C meningococcal polysaccharide-tetanus toxoid conjugates. J. Immunol. 127, 1011 (1981).

[96] Kahler, C. M., Martin, L. E., Shih, G. C., Rahman, M. M., Carlson, R. W. \& Stephens, D. $S$. The $(\alpha 2 \rightarrow 8)$-linked polysialic acid capsule and lipooligosaccharide structure both contribute to the ability of serogroup B Neisseria meningitidis to resist the bactericidal activity of normal human serum. Infection and immunity 66, 5939-5947 (1998).

[97] Tzeng, Y.-L. \& Stephens, D. S. Epidemiology and pathogenesis of Neisseria meningitidis. Microbes and infection 2, 687-700 (2000).

[98] Finne, J., Bitter-Suermann, D., Goridis, C. \& Finne, U. An IgG monoclonal antibody to group B meningococci cross-reacts with developmentally regulated polysialic acid units of glycoproteins in neural and extraneural tissues. J. Immunol. 138, 4402 (1987).

[99] Fang, X., Fang, Y., Liu, L., Liu, G. \& Wu, J. Mapping Paratope on Antithrombotic Antibody 6B4 to Epitope on Platelet Glycoprotein Ibalpha via Molecular Dynamic Simulations. PLoS ONE 7, e42263 (2012).

[100] Frank, S. A. Immunology and evolution of infectious disease. Chapter 4, Specificity and Cross-Reactivity (Princeton University Press, 2002).

[101] Kaur, I. P., Kakkar, V., Deol, P. K., Yadav, M., Singh, M. \& Sharma, I. Issues and concerns in nanotech product development and its commercialization. Journal of Controlled Release 193, 51-62 (2014).

[102] Wei, A., Mehtala, J. G. \& Patri, A. K. Challenges and opportunities in the advancement of nanomedicines. Journal of Controlled Release 164, 236-246 (2012).

[103] Borgos, S. E. F., Cornier, J., Owen, A., Kwade, A. \& Van de Voorde, M. in Pharmaceutical Nanotechnology: Innovation and Production 135-156 (Wiley-VCH Verlag GmbH \& Co. KGaA, 2017).

[104] Stern, S., McNeil, S., Patri, A. \& Dobrovolskaia, M. in Nanotechnology for Cancer Therapy 105-137 (CRC Press, 2006).

[105] NCL assay cascade protocols. https://ncl.cancer.gov/resources/assay-cascadeprotocols Consulted on August 2017 
[106] Ashford, M., Cornier, J., Owen, A., Kwade, A. \& Van de Voorde, M. in Pharmaceutical Nanotechnology: Innovation and Production 697-734 (Wiley-VCH Verlag GmbH \& Co. KGaA, 2017).

[107] Szebeni, J. \& Storm, G. Complement activation as a bioequivalence issue relevant to the development of generic liposomes and other nanoparticulate drugs. Biochemical and Biophysical Research Communications 468, 490-497 (2015).

[108] Moghimi, S.M. \& Farhangrazi, Z.S. Defining and characterizing nonbiological complex drugs (NBCDs) - is size enough? The case for liposomal doxorubicin generics ('liposomal nanosimilars') for injection. Generics and Biosimilars Initiative Journal 3, 56-57 (2014).

[109] Wibroe, P. P., Ahmadvand, D., Oghabian, M. A., Yaghmur, A. \& Moghimi, S. M. An integrated assessment of morphology, size, and complement activation of the PEGylated liposomal doxorubicin products Doxil ${ }^{\circledR}$, Caely $^{\circledR}{ }^{\circledR}$, DOXOrubicin, and SinaDoxosome. Journal of Controlled Release 221, 1-8 (2016).

[110] EU-NCL assay cascade protocols. http://www.euncl.eu/about-us/assay-cascade/ Consulted on August 2017

[111] Papaluca, M., Ehmann, F., Pita, R., Hernan, D., Cornier, J., Owen, A., Kwade, A. \& Van de Voorde, M. in Pharmaceutical Nanotechnology: Innovation and Production 497-520 (Wiley-VCH Verlag GmbH \& Co. KGaA, 2017).

[112] Xu, X. \& Khan, M. A. in Polymer Nanoparticles for Nanomedicines: A Guide for their Design, Preparation and Development (eds. Vauthier, C. \& Ponchel, G.) 615-633 (Springer International Publishing, 2016).

[113] Gao, X. \& Lowry, G. V. Progress towards standardized and validated characterizations for measuring physicochemical properties of manufactured nanomaterials relevant to nano health and safety risks. Nanolmpact 9, 14-30 (2018).

[114] Steinhäuser, K. G. \& Sayre, P. G. Reliability of methods and data for regulatory assessment of nanomaterial risks. Nanolmpact 7, 66-74 (2017).

[115] Desai, N. Challenges in Development of Nanoparticle-Based Therapeutics. The AAPS Journal 14, 282-295 (2012).

[116] Chen, R. \& Riviere, J. E. Biological and environmental surface interactions of nanomaterials: characterization, modeling, and prediction: Biological and environmental surface interactions of nanomaterials. Wiley Interdisciplinary Reviews: Nanomedicine and Nanobiotechnology 9, e1440 (2017).

[117] Ribeiro, A. R., Leite, P. E., Falagan-Lotsch, P., Benetti, F., Micheletti, C., Budtz, H. C., Jacobsen, N. R., Lisboa-Filho, P. N., Rocha, L. A., Kühnel, D., Hristozov, D. \& Granjeiro, J. $\mathrm{M}$. Challenges on the toxicological predictions of engineered nanoparticles. Nanolmpact 8, 59-72 (2017).

[118] FDA Nanotechnology Task Force Report 2007 https://www.fda.gov/ScienceResearch/ SpecialTopics/Nanotechnology/ucm2006659.htm (2007). Consulted on August 2017

[119] EMA Reflection paper on surface coatings: general issues for consideration regarding parenteral administration of coated nanomedicine products. http://www.ema.europa.eu/docs

Len GB/document library/Scientific guideline/2013/08/WC500147874.pdf

(2013). Consulted on August 2017

[120] EMA Reflection paper on the data requirements for intravenous liposomal products developed with reference to an innovator liposomal product. http://www.ema.europa.eu/docs/en GB 
Ldocument library/Scientific guideline/2013/03/WC500140351.pdf (2013). Consulted on August 2017

[121] EMA Reflection paper on the data requirements for intravenous iron-based nanocolloidal products developed with reference to an innovator medicinal product. http://www.ema.europa.eu/docs/en_GB/document_library/Scientific_guideline/2013/0 3/WC500140351.pdf (2015). Consulted on August 2017

[122] Pérez de la Ossa D.H. Quality aspects of Nano-based medicines. at SME Workshop: Focus on quality for medicines containing chemical entities. http://www.ema.europa.eu/docs/en GB/d

ocument library/Presentation/2014/04/WC500165444.pdf (2014). Consulted on August 2017

[123] Pena, C. A FDA Perspective on Nanomedicine - Current Initiatives in the US. http://www.ema.europa.eu/docs/en GB/document library/Presentation/2010/09/WC5 00096201.pdf (2010). Consulted on August 2017

[124] FDA guidance for industry: Safety of nanomaterials in cosmetic products. https://www.fda.gov/cosmetics/guidanceregulation/guidancedocuments/ucm300886.ht m (2014). Consulted on August 2017

[125] Tantra, R., Jarman, J. C. \& Robinson, K. N. in Nanomaterial Characterization 1-24 (John Wiley \& Sons, Inc, 2016).

[126] ISO/TR 13014:2012: Nanotechnologies - Guidance on Physico-Chemical Characterization of Engineered Nanoscale Materials for Toxicologic Assessment. ISO; 2012.

[127] OECD, Guidance on sample preparation and dosimetry for the safety testing of manufactured nanomaterials, in Working Party on Manufactured Nanomaterials. OECD; 2012.

[128] http://www.quality-assistance.com/analytical-services/nanomedicine-products Consulted on August 2017

[129] Ventola, C. L. The Nanomedicine Revolution: Part 3: Regulatory and Safety Challenges. Pharmacy and Therapeutics 37, 631-639 (2012).

[130] Clogston, J. D., Crist, R. M. \& McNeil, S. E. in Polymer Nanoparticles for Nanomedicines: A Guide for their Design, Preparation and Development (eds. Vauthier, C. \& Ponchel, G.) 187-203 (Springer International Publishing, 2016).

[131] ISO/TR 18196:2016(en): Nanotechnologies - Measurement technique matrix for the characterization of nano-objects. ISO; 2016.

[132] ISO 22412:2017 : Particle size analysis - Dynamic light scattering (DLS). ISO; 2017.

[133] Linsinger, T.P.J., Roebben, G., Gilliland, D., Calzolai, L., Rossi, F., Gibson, N. \& Klein, C. Requirements on measurements for the implementation of the European Commission definition of the term 'nanomaterial'. JRC Reference Report (2012).

[134] Bartczak, D. \& Goenaga-Infante, H. in Nanomaterial Characterization 63-80 (John Wiley \& Sons, Inc, 2016).

[135] Varenne, F., Makky, A., Gaucher-Delmas, M., Violleau, F. \& Vauthier, C. Multimodal Dispersion of Nanoparticles: A Comprehensive Evaluation of Size Distribution with 9 Size Measurement Methods. Pharmaceutical Research 33, 1220-1234 (2016).

[136] Tian, X., Nejadnik, M. R., Baunsgaard, D., Henriksen, A., Rischel, C. \& Jiskoot, W. A Comprehensive Evaluation of Nanoparticle Tracking Analysis (NanoSight) for Characterization of Proteinaceous Submicron Particles. Journal of Pharmaceutical Sciences 105, 3366-3375 (2016). 
[137] Vogel, R., Willmott, G., Kozak, D., Roberts, G. S., Anderson, W., Groenewegen, L., Glossop, B., Barnett, A., Turner, A. \& Trau, M. Quantitative Sizing of Nano/Microparticles with a Tunable Elastomeric Pore Sensor. Anal. Chem. 83, 3499-3506 (2011).

[138] Mat Azmi, I. D., Wu, L., Wibroe, P. P., Nilsson, C., Østergaard, J., Stürup, S., Gammelgaard, B., Urtti, A., Moghimi, S. M. \& Yaghmur, A. Modulatory Effect of Human Plasma on the Internal Nanostructure and Size Characteristics of Liquid-Crystalline Nanocarriers. Langmuir 31, 5042-5049 (2015).

[139] Blundell, E. L. C. J., Healey, M. J., Holton, E., Sivakumaran, M., Manstana, S. \& Platt, M. Characterisation of the protein corona using tunable resistive pulse sensing: determining the change and distribution of a particle's surface charge. Analytical and Bioanalytical Chemistry 408, 5757-5768 (2016).

[140] Arancon, R. A. D., Lin, S. H. T., Chen, G., Lin, C. S. K., Lai, J., Xu, G. \& Luque, R. Nanoparticle tracking analysis of gold nanomaterials stabilized by various capping agents. RSC Adv. 4, 17114-17119 (2014).

[141] ISO 19430:2016(en): Particle size analysis - Particle tracking analysis (PTA) method. ISO; 2016.

[142] ISO 13318-1:2001(en) Determination of particle size distribution by centrifugal liquid sedimentation methods - Part 1: General principles and guidelines. ISO; 2001.

[143] Hu, M., Vink, M., Kim, C., Derr, K., Koss, J., D’Amico, K., Cheng, A., Pulokas, J., Ubarretxena-Belandia, I. \& Stokes, D. Automated Electron Microscopy for Evaluating Two-dimensional Crystallization of Membrane Proteins. Journal of Structural Biology 171, 102-110 (2010).

[144] Laramy, C. R., Brown, K. A., O’Brien, M. N. \& Mirkin, C. A. High-Throughput, Algorithmic Determination of Nanoparticle Structure from Electron Microscopy Images. ACS Nano 9, 12488-12495 (2015).

[145] Zhang, Y., Hung, T., Song, J. \& He, J. Electron microscopy: essentials for viral structure, morphogenesis and rapid diagnosis. Science China Life Sciences 56, 421-430 (2013).

[146] Vale, F. F., Correia, A. C., Matos, B., Moura Nunes, J. F. \& Alves de Matos, A. P. Applications of transmission electron microscopy to virus detection and identification. Microscopy: science, technology, applications and education 1, (2010).

[147] Goldsmith, C. S. \& Miller, S. E. Modern Uses of Electron Microscopy for Detection of Viruses. Clinical Microbiology Reviews 22, 552-563 (2009).

[148] Plascencia-Villa, G., Bahena, D., Rodríguez, A. R., Ponce, A. \& José-Yacamán, M. Advanced microscopy of star-shaped gold nanoparticles and their adsorption-uptake by macrophages. Metallomics 5, 242 (2013).

[149] Zhao, Y., Wang, Y., Ran, F., Cui, Y., Liu, C., Zhao, Q., Gao, Y., Wang, D. \& Wang, S. A comparison between sphere and rod nanoparticles regarding their in vivo biological behavior and pharmacokinetics. Scientific Reports 7, (2017).

[150] Khodashenas, B. \& Ghorbani, H. R. Synthesis of silver nanoparticles with different shapes. Arabian Journal of Chemistry (2015).

[151] Toy, R., Peiris, P.M., Ghaghada, K.B. \& Karathanasis E. Shaping cancer nanomedicine: the effect of particle shape on the in vivo journey of nanoparticles. Nanomedicine 9, 121134 (2013).

[152] Zhao, J., Lu, H., Wong, S., Lu, M., Xiao, P. \& Stenzel, M. H. Influence of nanoparticle shapes on cellular uptake of paclitaxel loaded nanoparticles in 2D and 3D cancer models. Polym. Chem. 8, 3317-3326 (2017). 
[153] Xie, X., Liao, J., Shao, X., Li, Q. \& Lin, Y. The Effect of shape on Cellular Uptake of Gold Nanoparticles in the forms of Stars, Rods, and Triangles. Scientific Reports 7, (2017).

[154] Allen, C., Qiu, T. A., Pramanik, S., Buchman, J. T., Krause, M. O. P. \& Murphy, C. J. Research highlights: investigating the role of nanoparticle surface charge in nano-bio interactions. Environ. Sci.: Nano 4, 741-746 (2017).

[155] Varenne, F., Botton, J., Merlet, C., Beck-Broichsitter, M., Legrand, F.-X. \& Vauthier, C. Standardization and validation of a protocol of size measurements by dynamic light scattering for monodispersed stable nanomaterial characterization. Colloids and Surfaces A: Physicochemical and Engineering Aspects 486, 124-138 (2015).

[156] Varenne, F., Botton, J., Merlet, C., Vachon, J.-J., Geiger, S., Infante, I. C., Chehimi, M. M. \& Vauthier, C. Standardization and validation of a protocol of zeta potential measurements by electrophoretic light scattering for nanomaterial characterization. Colloids and Surfaces A: Physicochemical and Engineering Aspects 486, 218-231 (2015).

[157] Belsey, N. A., Shard, A. G. \& Minelli, C. in Nanomaterial Characterization 153-178 (John Wiley \& Sons, Inc, 2016).

[158] Rabanel, J.-M., Hildgen, P. \& Banquy, X. Assessment of PEG on polymeric particles surface, a key step in drug carrier translation. Journal of Controlled Release 185, 71-87 (2014).

[159] Baer, D. R., Engelhard, M. H., Johnson, G. E., Laskin, J., Lai, J., Mueller, K., Munusamy, P., Thevuthasan, S., Wang, H., Washton, N., Elder, A., Baisch, B. L., Karakoti, A., Kuchibhatla, S. V. N. T. \& Moon, D. Surface characterization of nanomaterials and nanoparticles: Important needs and challenging opportunities. Journal of Vacuum Science \& Technology A: Vacuum, Surfaces, and Films 31, 050820 (2013).

[160] Kim, Y.-P., Shon, H. K., Shin, S. K. \& Lee, T. G. Probing nanoparticles and nanoparticleconjugated biomolecules using time-of-flight secondary ion mass spectrometry. Mass Spectrometry Reviews 34, 237-247 (2015).

[161] Ambardekar, V. V. \& Stern, S. T. in Non-Biological Complex Drugs (eds. Crommelin, D. J. A. \& de Vlieger, J. S. B.) 20, 261-287 (Springer International Publishing, 2015).

[162] Charrueau, C. \& Zandanel, C. in Polymer Nanoparticles for Nanomedicines: A Guide for their Design, Preparation and Development (eds. Vauthier, C. \& Ponchel, G.) 439-503 (Springer International Publishing, 2016).

[163] Leroux, J.-C. Drug Delivery: Too Much Complexity, Not Enough Reproducibility? Angewandte Chemie International Edition (2017). doi:10.1002/anie.201709002

[164] Bertrand, N., Grenier, P., Mahmoudi, M., Lima, E. M., Appel, E. A., Dormont, F., Lim, J.-M., Karnik, R., Langer, R. \& Farokhzad, O. C. Mechanistic understanding of in vivo protein corona formation on polymeric nanoparticles and impact on pharmacokinetics. Nature Communications 8, (2017).

[165] Crist, R. \& McNeil, S. Nanotechnology for Treating Cancer: Pitfalls and Bridges on the Path to Nanomedicines, 2015. https://www.cancer.gov/research/keyinitiatives/ras $\angle$ rascentral/blog/2015/nanomedicines Consulted on August 2017.

[166] Bai, X., Liu, F., Liu, Y., Li, C., Wang, S., Zhou, H., Wang, W., Zhu, H., Winkler, D. A. \& Yan, B. Toward a systematic exploration of nano-bio interactions. Toxicology and Applied Pharmacology 323, 66-73 (2017).

[167] Paliwal, R., Babu, R. J. \& Palakurthi, S. Nanomedicine Scale-up Technologies: Feasibilities and Challenges. AAPS PharmSciTech 15, 1527-1534 (2014). 
[168] DeLong, R. \& Husrt, M. Two-dimensional fluorescence difference spectroscopy characterization of nanoparticles and their interactions. Patent US 20170131272 A1. (2017).

[169] Kelly, P. M., Åberg, C., Polo, E., O’Connell, A., Cookman, J., Fallon, J., Krpetić, Ž. \& Dawson, K. A. Mapping protein binding sites on the biomolecular corona of nanoparticles. Nature Nanotechnology 10, 472-479 (2015).

[170] Kelly, P. \& Dawson, K. A method of labelling a target molecule forming part of a corona of molecules on a surface of a nanosized object. Patent US 20170146527. (2017).

[171] Zhang, W., Ma, M., Zhang, X., Zhang, Z., Saleh, S. M. \& Wang, X. Fluorescent proteins as efficient tools for evaluating the surface PEGylation of silica nanoparticles. Methods and Applications in Fluorescence 5, 024003 (2017).

[172] Anderson, S. R., Parmiter, D., Baxa, U. \& Nagashima, K. in Characterization of Nanoparticles Intended for Drug Delivery (ed. McNeil, S. E.) 1682, 65-71 (Springer New York, 2018).

[173] Lin, S., Mortimer, M., Chen, R., Kakinen, A., Riviere, J. E., Davis, T. P., Ding, F. \& Ke, P. C. NanoEHS beyond toxicity - focusing on biocorona. Environ. Sci.: Nano 4, 1433-1454 (2017).

[174] Pisani, C., Gaillard, J. C., Dorandeu, C., Charnay, C., Guari, Y., Chopineau, J., Devoisselle, J. M., Armengaud, J. \& Prat, O. Experimental separation steps influence the protein content of corona around mesoporous silica nanoparticles. Nanoscale 9, 5769-5772 (2017).

[175] Lundqvist, M., Augustsson, C., Lilja, M., Lundkvist, K., Dahlbäck, B., Linse, S. \& Cedervall, T. The nanoparticle protein corona formed in human blood or human blood fractions. PLOS ONE 12, e0175871 (2017).

[176] Forest, V. \& Pourchez, J. The nanoparticle protein corona: The myth of average. Nano Today 11, 700-703 (2016).

[177] Feiner-Gracia, N., Beck, M., Pujals, S., Tosi, S., Mandal, T., Buske, C., Linden, M. \& Albertazzi, L. Super-Resolution Microscopy Unveils Dynamic Heterogeneities in Nanoparticle Protein Corona. Small 13, 1701631 (2017).

[178] Kuruvilla, J., Farinha, A. P., Bayat, N. \& Cristobal, S. Surface proteomics on nanoparticles: a step to simplify the rapid prototyping of nanoparticles. Nanoscale Horiz. 2, 55-64 (2017).

[179] Nasir, I., Fatih, W., Svensson, A., Radu, D., Linse, S., Cabaleiro Lago, C. \& Lundqvist, M. High Throughput Screening Method to Explore Protein Interactions with Nanoparticles. PLOS ONE 10, e0136687 (2015).

[180] Xia, X.-R., Monteiro-Riviere, N. A. \& Riviere, J. E. An index for characterization of nanomaterials in biological systems. Nature Nanotechnology 5, 671-675 (2010).

[181] Chen, R. \& Riviere, J. E. in Modelling the Toxicity of Nanoparticles (eds. Tran, L., Bañares, M. A. \& Rallo, R.) 947, 207-253 (Springer International Publishing, 2017).

[182] Sanvito, T., Bigini, P., Cavanna, M. V., Fiordaliso, F., Violatto, M. B., Talamini, L., Salmona, M., Milani, P. \& Potenza, M. A. C. Single particle extinction and scattering optical method unveils in real time the influence of the blood components on polymeric nanoparticles. Nanomedicine: Nanotechnology, Biology and Medicine (2017).

[183] Sikora, A., Shard, A. G. \& Minelli, C. Size and ל-Potential Measurement of Silica Nanoparticles in Serum Using Tunable Resistive Pulse Sensing. Langmuir 32, 2216-2224 (2016). 
[184] Szebeni, J. Complement activation-related pseudoallergy: A new class of druginduced acute immune toxicity. Toxicology 216, 106-121 (2005).

[185] Szebeni, J. Hemocompatibility testing for nanomedicines and biologicals: predictive assays for complement mediated infusion reactions. European Journal of Nanomedicine 4, (2012).

[186] Coty, J.-B., Varenne, F., Vachon, J.-J. \& Vauthier, C. Serial multiple crossed immunoelectrophoresis at a microscale: A stamp-sized 2D immunoanalysis of protein C3 activation caused by nanoparticles: Proteomics and 2-DE. ELECTROPHORESIS 37, 24012409 (2016). 